\title{
Article \\ Bmp Signal Gradient Modulates Convergent Cell Movement via Xarhgef3.2 during Gastrulation of Xenopus Embryos
}

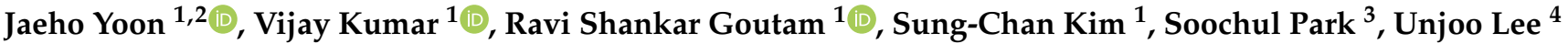 \\ and Jaebong $\operatorname{Kim}^{1, *}$ \\ 1 Department of Biochemistry, Institute of Cell Differentiation and Aging, College of Medicine, \\ Hallym University, Chuncheon 24252, Korea; jaeho.yoon@nih.gov (J.Y.); vijay10187@gmail.com (V.K.); \\ ravi2005gautam@gmail.com (R.S.G.); biokim@hallym.ac.kr (S.-C.K.) \\ 2 National Cancer Institute, Frederick, MD 21702, USA \\ 3 Department of Biological Sciences, Sookmyung Women's University, Seoul 04310, Korea; \\ scpark@sookmyung.ac.kr \\ 4 Department of Electrical Engineering, Hallym University, Chuncheon 24252, Korea; ejlee@hallym.ac.kr \\ * Correspondence: jbkim@hallym.ac.kr
}

Citation: Yoon, J.; Kumar, V.; Goutam, R.S.; Kim, S.-C.; Park, S.; Lee, U.; Kim, J. Bmp Signal Gradient Modulates Convergent Cell Movement via Xarhgef3.2 during Gastrulation of Xenopus Embryos. Cells 2022, 11, 44 https://doi.org/10.3390/ cells11010044

Academic Editor: Blanca Herrera

Received: 18 October 2021

Accepted: 21 December 2021

Published: 24 December 2021

Publisher's Note: MDPI stays neutral with regard to jurisdictional claims in published maps and institutional affiliations.

Copyright: (C) 2021 by the authors. Licensee MDPI, Basel, Switzerland. This article is an open access article distributed under the terms and conditions of the Creative Commons Attribution (CC BY) license (https:// creativecommons.org/licenses/by/ $4.0 /)$.

\begin{abstract}
Gastrulation is a critical step in the establishment of a basic body plan during development. Convergence and extension (CE) cell movements organize germ layers during gastrulation. Noncanonical Wnt signaling has been known as major signaling that regulates CE cell movement by activating Rho and Rac. In addition, Bmp molecules are expressed in the ventral side of a developing embryo, and the ventral mesoderm region undergoes minimal CE cell movement while the dorsal mesoderm undergoes dynamic cell movements. This suggests that Bmp signal gradient may affect $\mathrm{CE}$ cell movement. To investigate whether Bmp signaling negatively regulates $\mathrm{CE}$ cell movements, we performed microarray-based screening and found that the transcription of Xenopus Arhgef3.2 (Rho guanine nucleotide exchange factor) was negatively regulated by Bmp signaling. We also showed that overexpression or knockdown of Xarhgef3.2 caused gastrulation defects. Interestingly, Xarhgef3.2 controlled gastrulation cell movements through interacting with Disheveled (Dsh2) and Dsh2-associated activator of morphogenesis 1 (Daam1). Our results suggest that Bmp gradient affects gastrulation cell movement (CE) via negative regulation of Xarhgef3.2 expression.
\end{abstract}

Keywords: Bmp; Wnt-PCP; gastrulation; Xarhgef3.2; Disheveled; daam1; convergent extension; Xenopus

\section{Introduction}

Cell fate determination and gastrulation-induced movement are two most important events in early embryogenesis. In Xenopus, after fertilization, a single-cell embryo undergoes sequential cleavages with the cells at the blastula stage forming three germ layers, referred to as ectoderm, mesoderm, and endoderm [1]. The establishment of these germ layers utilizes several signaling pathways that include Bmp, TGF- $\beta$, FGF, and Wnt/ $\beta$-catenin signaling. Movement of these specialized germ layers to their specific positions marks the onset of gastrulation in a process termed convergence and extension (CE) movements. This phenomenon of gastrulation cell movement is mainly governed by Wnt-planar cell polarity (Wnt-PCP) signaling [2]. Furthermore, during gastrulation, the dorsal mesoderm and neural tissues converge and extend dramatically, pushing the future head tissues away from the tail to form extended anteroposterior body axis [3]. These events occur in an orderly fashion, involving different signaling cascades, but the correlation between these two processes has not been investigated in detail. Cell fate determination for an early vertebrate embryo is predominantly brought about by Bmp gradient signaling in the ventral region and, also in part, by BMP antagonists secreted in the dorsal region of the Spemann organizer $[1,4,5]$. The Spemann organizer itself maintains dorsoventral patterning by expressing Bmp antagonists such as chordin (chrd), noggin (nog), and follistatin ( $f o l$ ) [6]. For Bmp4, its gradient specifies the ventral posterior zone and inhibits neurogenesis [7,8]; 
this is mediated by modulating the activities of various R-Smads such as Smad 1/5/8 and regulating target gene expression [9]. There have also been reports in which the Bmp4 signaling gradient modulates CE movement. In zebrafish, for example, the Bmp signaling gradient plays an instructive role in regulating CE movement during gastrula [10]. In addition, overexpression of Bmp inhibits activin-induced CE in Xenopus animal caps (ACs) [11], while blocking Bmp can induce CE of the ventral marginal zone [12].

In all, Bmp signaling gradient is a major determinant for asymmetric development during embryogenesis in vertebrates. In Xenopus embryos, the Bmp4 gradient is generated by cells located in the embryonic ventral region and decreases towards the dorsal side of an embryo. As for the CE activity, it is strong near the dorsal area and becomes weak near the ventral side of embryos. This arrangement implies that Bmp signaling gradient is somehow negatively involved in the regulation of CE cell movement in Xenopus; however, the cause and effects in such a scenario are largely unknown. CE actively occurs in the dorsal mesoderm and the neural ectoderm to narrow the width of these tissues and widen their length along the anteroposterior axis, giving rise to the basic vertebrate body plan. For gastrulation, CE cell movement is precisely regulated by noncanonical Wnt signaling [13-16], and Wnt-PCP signaling has been described as the major signaling pathway regulating CE. Wnt-PCP signaling utilizes noncanonical Wnt signaling components such as Frizzled (Fz), Dsh2, Dsh2-associated activator of morphogenesis 1 (Daam1), guanine nucleotide exchange factors (RhoGEF), and small GTPases such as RhoA, Rac1, and Cdc42. Rho GTPases have already been shown to be involved in cell adhesion and cell cytokinesis in Xenopus [17-20] and in CE movement during gastrulation [21-24]. Activation of Rho GTPases is mediated by guanine nucleotide exchange factors (GEFs) $[25,26]$ that catalyze GDP-to-GTP exchange, leading to Rho activation. About 85 RhoGEFs have been identified in vertebrates, and of these, Xwgef (arhgef19) and Xnet1 (arhgef8) have been studied in Xenopus gastrulation cell movement $[27,28]$. Xwgef and Xnet1 are homologous to mammalian RhoA-specific GEFs. Both overexpression and mutant versions of Xnet1 critically affect gastrulation cell movement in Xenopus [28]. Interestingly, overexpression of Xwgef is able to rescue CE suppression triggered by dominant-negative Wnt11, and downregulation of Xwgef leads to inhibition of CE movement in Xenopus [27]. An intracellular Wnt signaling element, Dsh2, also plays a major role in the CE process in Xenopus [13-16]. Both Xwgef and Xnet1 control CE movement via interacting with Dsh2 through RhoA activation [27]. Nevertheless, expression of Xwgef and Xnet1 is ubiquitous even in the ventral marginal zone (VMZ) and the animal pole region, although these regions undergo weak CE cell movements. Given many important regulatory processes of Xenopus embryogenesis are mediated by Rho GTPases, the regulatory mechanisms of Rho GTPases still remain to be worked out as only few RhoGEFs have been well-characterized in the early development of an organism.

In the current study, we hypothesized that cell fate determination and subsequent gastrulation movement are linked via Bmp gradient, and we aimed to uncover an interconnected Wnt-PCP molecule whose expression is governed by BMP gradient, linking the two events. Our Affymetrix microarray data revealed that several ESTs associated with cell movement were markedly affected by the Bmp4 signaling gradient in the dorsal marginal zone (DMZ) of Xenopus. Among these ESTs, X1.3374 encodes the guanine nucleotide exchange factor for RhoA, Xarhgef3.2.L (Xarhgef3.2), and is similar to human Arhgef3 [29,30]. Compared to Xwgef and Xnet1, endogenous expression of Xarhgef3.2 was progressively upregulated by Bmp4 inhibition in ACs of the gastrula stage. Overexpression and knockdown of Xarhgef3.2 severely impaired gastrulation movement in the Xenopus embryos. We also show that Xarhgef3.2 activates RhoA but not Rac1 or Cdc42 via a physical interaction with Dsh2 and Daam1. Taken together, our data point to Xarhgef3.2 as a key regulator of $\mathrm{CE}$ cell movement, its expression being negatively modulated by the Bmp4 signaling gradient. Thus, we propose that BMP4 signaling negatively regulates gastrulation cell movement by modulating transcription of Xarhgef3.2, a noncanonical Wnt component gene, during the early gastrula of Xenopus embryos. 


\section{Materials and Methods}

\subsection{Ethics Statement}

The animal studies were conducted in accordance with the approved protocols and oversight from the Institutional Animal Care and Use Committee (IACUC) of Hallym University (Hallym 2019-79, 2019-80). All our research team members attended educational and training courses for the appropriate care and use of experimental animals. Adult $X$. laevis were maintained in suitable containers under a $12 \mathrm{~h}$ light/dark (LD 12:12 h) cycle at $18{ }^{\circ} \mathrm{C}$, tended by authorized personnel, according to the guidelines of the Institute of Laboratory Animal Resources of Hallym University.

\subsection{Embryos Injection and Explant Culture}

Xenopus laevis were obtained from the Korean Xenopus Resource Center for Research (Seoul, Korea). The embryos were injected following in vitro fertilization of eggs [31], the frogs having been induced by injection of 500 units of human chorionic gonadotropin (Sigma, St. Louis, MI, USA). RNAs were injected into the embryo animal pole at the one- or two-cell stage and then cultured in 30\% Marc's Modified Ringer's (MMR) solution. RNAs of $\beta$-galactosidase ( $1 \mathrm{ng}$ /embryo) or eGFP ( $1 \mathrm{ng} /$ embryo) were injected as control to check for gastrulation defects at stage 11 [32]. Developmental stages were designated according to the Nieuwkoop and Faber Normal Table of Xenopus laevis (Daudin) [33]. Animal caps (ACs) were then dissected from the injected and noninjected embryos at stage 8.0-8.5 and incubated in $1 \times$ L-15 growth medium (Gibco/Thermo Fisher, Waltham, MA, USA) until stages 11 and 24 in preparation for RT-PCR.

\subsection{Sample Preparation and Microarray Analysis}

A dominant negative BMP type I receptor (DNBR) (lacking the serine/threonine kinase domain) [34,35] RNA (500 pg/embryo) was injected into the embryo animal pole at the one- or two-cell stage and then cultured in 30\% MMR solution. Animal caps (ACs) were dissected from the injected and noninjected embryos at stage 8-9 and cultured until stage 11 (control and DNBR ACs) [36]. ACs from the noninjected embryos were also cultured to stage 11 with activin $(25 \mathrm{ng} / \mathrm{mL}$ ) or basic Fgf (bFgf, $100 \mathrm{ng} / \mathrm{mL}$ ) (activin vs. Fgf ACs) in 67\% Leibovitz's L-15 medium (Gibco, Waltham, MA, USA) supplemented with $0.3 \mathrm{mg} / \mathrm{mL}$ L-glutamine, $7 \mathrm{mM}$ Tris- $\mathrm{HCl}$, pH 7.5, and $50 \mu \mathrm{g} / \mathrm{mL}$ gentamicin. For each microarray experiment, about $500 \mathrm{ACs}$ were harvested and stored in RNAlater (Qiagen, Hilden, Germany), an RNA stabilization reagent, at $4{ }^{\circ} \mathrm{C}$ until RNA extraction. Total RNA was extracted from four groups of the ACs (control, DNBR, activin, and Fgf) with an RNeasy Mini kit (Qiagen, Hilden, Germany) following the manufacturer's instructions. Microarray experiments were performed by Seoulin Bioscience (Seoul, Korea) with an Affymetrix Xenopus Genome Gene Chip (Affymetrix) and described on their website (www. seoulin.co.kr, accessed on 25 June 2011).

\subsection{Microarray Data Normalization, Analysis, and Phylogenetic Tree}

Signals from the four groups of samples were normalized and analyzed by Seoulin Bioscience (Seoul, Korea). We presented the gene lists of transcripts showing a higher than $\log _{2}$-fold change when compared with the $\log _{2}$ value of the control signal (see the Supplementary Tables). The selected EST gene was used to perform the experiments [36,37]. The phylogenetic tree of arhgef3 and orthologs was built using Clustal Omega (https: / /www. ebi.ac.uk/Tools/msa/clustalo/ (accessed on 16 December 2021) and iTOL (https: / / itol.embl. de/, accessed on 16 December 2021) [38]. The protein sequences in the FASTA format were downloaded from Uniprot (https: / / www.uniprot.org/, accessed on 15 December 2021). The Supplementary Tables provides details of protein sequences and accession numbers.

\subsection{RNA Isolation and Reverse Transcription Polymerase Chain Reaction (RT-PCR)}

Total RNA was extracted from either the whole embryos or the cultured ACs with the TRIzol reagent (Life Technologies, Carlsbad, CA, USA) following the manufacturer's in- 
structions. RT-PCR was performed according to the following parameters: denaturation at $94{ }^{\circ} \mathrm{C}$ for $5 \mathrm{~min}, 19-30$ cycles of melting at $94{ }^{\circ} \mathrm{C}$ for $1 \mathrm{~min}$, annealing at a given temperature for $1 \mathrm{~min}$, and extension at $72{ }^{\circ} \mathrm{C}$ for $1 \mathrm{~min}$. Amplification and primer conditions were as described at the Xenopus Molecular Marker Resource (XMMR; University of Texas, Austin, TX, USA) unless mentioned in Table 1. ODC or EF1 $\alpha$ was used as a control to normalize the amount of cDNA used. The details on the primers are given in Table 1.

Table 1. Primers used for RT-PCR amplification.

\begin{tabular}{|c|c|c|}
\hline Gene Name & Sequence $\left(5^{\prime}\right.$ to $\left.3^{\prime}\right)$ & References \\
\hline \multirow{2}{*}{ Actin } & F-GCTGACAGAATGCAGAAG & \multirow{2}{*}{ [36] } \\
\hline & R-TTGCTTGGAGGAGTGTGT & \\
\hline \multirow{2}{*}{ Chordin } & F-TTAGAGAGGAGAGCAACTCGGGCAAT & \multirow{2}{*}[39]{} \\
\hline & R-GTGCTCCTGTTGCGAAACTCTACAGA & \\
\hline \multirow{2}{*}{ Edd } & F-CTCGCTCTGGACAAAACTC & \multirow{2}{*}{ [36] } \\
\hline & R-GAGCTTCTTGATGGGAATG & \\
\hline \multirow{2}{*}{ Gata2 } & F-AGGAACTTTCCAGGTGCATGCAGGAG & \multirow{2}{*}{ [36] } \\
\hline & R-CCGAGGTGCAAATTATTATGTTAC & \\
\hline \multirow{2}{*}{ Globin } & F-CATGGCTCTGCTGATCTGCCAACCAC & \multirow{2}{*}[36]{} \\
\hline & R-CCCAGGCTGGTGAGCTGCCCTTGCTG & \\
\hline \multirow{2}{*}{ Gsc } & F-GCTGATTCCACCAGTGCCTCACCAG & \multirow{2}{*}[39]{} \\
\hline & R-GGTCCTGTGCCTCCTCCTCCTCCTG & \\
\hline \multirow{2}{*}{ Hoxb9 } & F-TACTTACGGGCTTGGCTGGA & \multirow{2}{*}{ [36] } \\
\hline & R-AGCGTGTAACCAGTTGGCTG & \\
\hline \multirow{2}{*}{ Mixer } & F-CACCAGCCCAGCACTTAACC & \multirow{2}{*}[36]{} \\
\hline & R-CAATGTCACATCAACTGAAG & \\
\hline \multirow{2}{*}{ Ncam } & F-CACAGTTCCACCAAATGC & \multirow{2}{*}[36]{} \\
\hline & R-GGAATCAAGCGGTACAGA & \\
\hline \multirow{2}{*}{ XVent1.1 (Ventx1.2) } & F-TTCCCTTCAGCATGGTTCAAC & \multirow{2}{*}[40]{} \\
\hline & R-GCATCTCCTTGGCATATTTGG & \\
\hline \multirow{2}{*}{ PV.1 (Ventx1.1) } & F-CCTTCAGCATGGTTCAACAG & \multirow{2}{*}[40]{} \\
\hline & R-CATCCTTCTTCCTTGGCATC & \\
\hline \multirow{2}{*}{ Wnt11 (Wnt11b) } & F-TGACAGCTGCAACCTCATGT & \multirow{2}{*}{ Current study } \\
\hline & R-ACAGAGGGCTGTCAGTGCTT & \\
\hline \multirow{2}{*}{ Xarhgef3.2 } & F-ACСТСТСТCAAGAGTCACATCAC & \multirow{2}{*}{ Current study } \\
\hline & R-TACAGTAGCTGTCGTAGGAGTTC & \\
\hline \multirow{2}{*}{ Xbra } & F-GGATCGTTATCACCTCTG & \multirow{2}{*}[36]{} \\
\hline & R-GTGTAGTCTGTAGCAGCA & \\
\hline Y 1 & F-TGGTGTTGAACAAGTGCAGG & 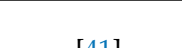 \\
\hline Xk81 & R-ACCTCCTCGACAATGGTCTT & [41] \\
\hline Y & F-GACAAATTGGAGTACCTC & rag \\
\hline Xnet1 & R-CACCAAAGTCTCTTTTTTCTGCGG & [28] \\
\hline Y & F-GAGGTGCCGGGGGAGGTTTTC & \\
\hline$\lambda w g e r$ & R-GGGGGCCCGTCGCTGTAGTT & 27 \\
\hline & F-TCTCAGGATCTGAACACCT & 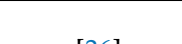 \\
\hline Zic3 & R-CCCTATAAGACAAGGAATAC & [36] \\
\hline תחת & F-GTCAATGATGGAGTGTATGGATC & 500 \\
\hline ODC & R-TCCATTCCGCTCTCCTGAGCAC & \\
\hline
\end{tabular}




\subsection{In Vitro Transcription}

The Xarhgef3.2 mRNA used for microinjection was produced by in vitro transcription. PCR-amplified Xarhgef3.2.L (Xarhgef3.2.) cDNA was inserted using the EcoRI and XhoI sites of the pCS2+ vector. The cDNAs were linearized using Asp718 and used for in vitro synthesis of capped mRNA using in an vitro transcription kit (Ambion, Austin, TX, USA) in accordance with the manufacturer's instructions. The synthetic RNA was quantified by means of ethidium bromide staining, compared with standard RNA.

\subsection{Embryos and Whole-Mount In Situ Hybridization}

Wild-type and albino Xenopus laevis embryos were obtained by hormone-induced egg laying and in vitro fertilization using standard methods. Whole-mount in situ hybridization was performed as described previously [42], with modifications [43]. For double-staining analysis, digoxigenin-UTP- and fluorescein-UTP-labeled RNA probes were used. After the first staining with NBT/BCIP, the enzyme reaction was stopped by heating the embryos for $20 \mathrm{~min}$ in $0.1 \times$ MBS supplemented with $10 \mathrm{M}$ EDTA. Staining for the second transcript was as for the first one, but using Fast Red (Boehringer Mannheim, Mannheim, Germany) as a dye. The probes were prepared using digoxigenin or fluorescein RNA-labeling mixes (Boehringer Mannheim) and subsequently purified using an in vitro transcription kit (Ambion, Austin, TX, USA). The probes used were Xarhgef3.2, cut with EcoRI and transcribed with the T7 RNA polymerase.

\subsection{Morpholino Oligos}

Morpholino oligos (Gene Tools, Philomath, OR, USA) as antisense oligodeoxynucleotides were used for loss-of-function studies. The base composition of the antisense oligodeoxynucleotide was the 25-mer morpholino, 5'CTG GCA GGT TCA CTG GTC ACA ATT A $3^{\prime}$ (Xarhgef3.2 MO), which targeted the 5' UTR region of the Xarhgef3.2.L mRNA. The specificity of MO was examined by means of Western blot detection of the Flagged protein after injection of the $5^{\prime} U T R$-Xarhgef3.2-3Flag construct. The MO was against the $5^{\prime}$ UTR region of $5^{\prime} U T R$-Xarhgef3.2 (including the endogenous target). The addback $5^{\prime}-3 F l a g$ version was tagged in its $5^{\prime}$ region and its message would not bind the $\mathrm{MO}$ and thus would be expressed. The MO was confirmed to block target 5'UTR-Xarhgef3.2-3Flag without affecting amounts of endogenous Xarhgef3.2 RNA.

\section{Results}

\subsection{Bmp Signal Gradient Modulates Xarhgef3.2 Transcription}

In Xenopus, Bmp inhibition in the VMZ produces a partial secondary axis in the whole embryo [44]. To examine the involvement of CE movement in partial axis formation by $\mathrm{BMP}$ inhibition, the role of Bmp, an essential component of CE movement, was examined using the dominant negative mutant forms of the Bmp receptor (DNBR) and RhoA (DNRhoA). Dnbr (500 pg/embryo) was injected in the VMZ of the four-cell stage embryo, and the injection in the VMZ produced a partial secondary axis (Figure 1B). To examine the involvement of CE movement using a Rho downstream of the Wnt-PCP component [45], dnbr (500 pg/embryo) and DN-RhoA (300 pg/embryo) were co-injected in the VMZ region of the four-cell stage embryos. As expected, the partial secondary axis formed by inhibition of Bmp disappeared by co-injection of $D N-R h o A$ (Figure 1C). Another experiment using the $X$-gal tracer suggested that formation of a partial secondary axis may require fate change of VMZ cells as well as activation of Wnt-PCP signaling in those cells since BMP-inhibited cells of the VMZ remained part of an embryo without producing a secondary axis in the embryo by $D N-R h o A$ co-injection (Supplementary Figure S1A). We confirmed that BMP inhibition in the VMZ led to the conversion of the VMZ to the DMZ in character. The VMZ explants injected with DNBR resulted in a similar elongation phenotype for that of the DMZ explants (Supplementary Figure S1B). The expression levels of the organizer (dorsal mesoderm)-specific gene, chordin, were increased; at the same time, the levels of the ventral 
specific gene, ventx1.1, were decreased, and there was no change in the expression of the pan-mesoderm marker, $x b r a$ (Supplementary Figure S1B).

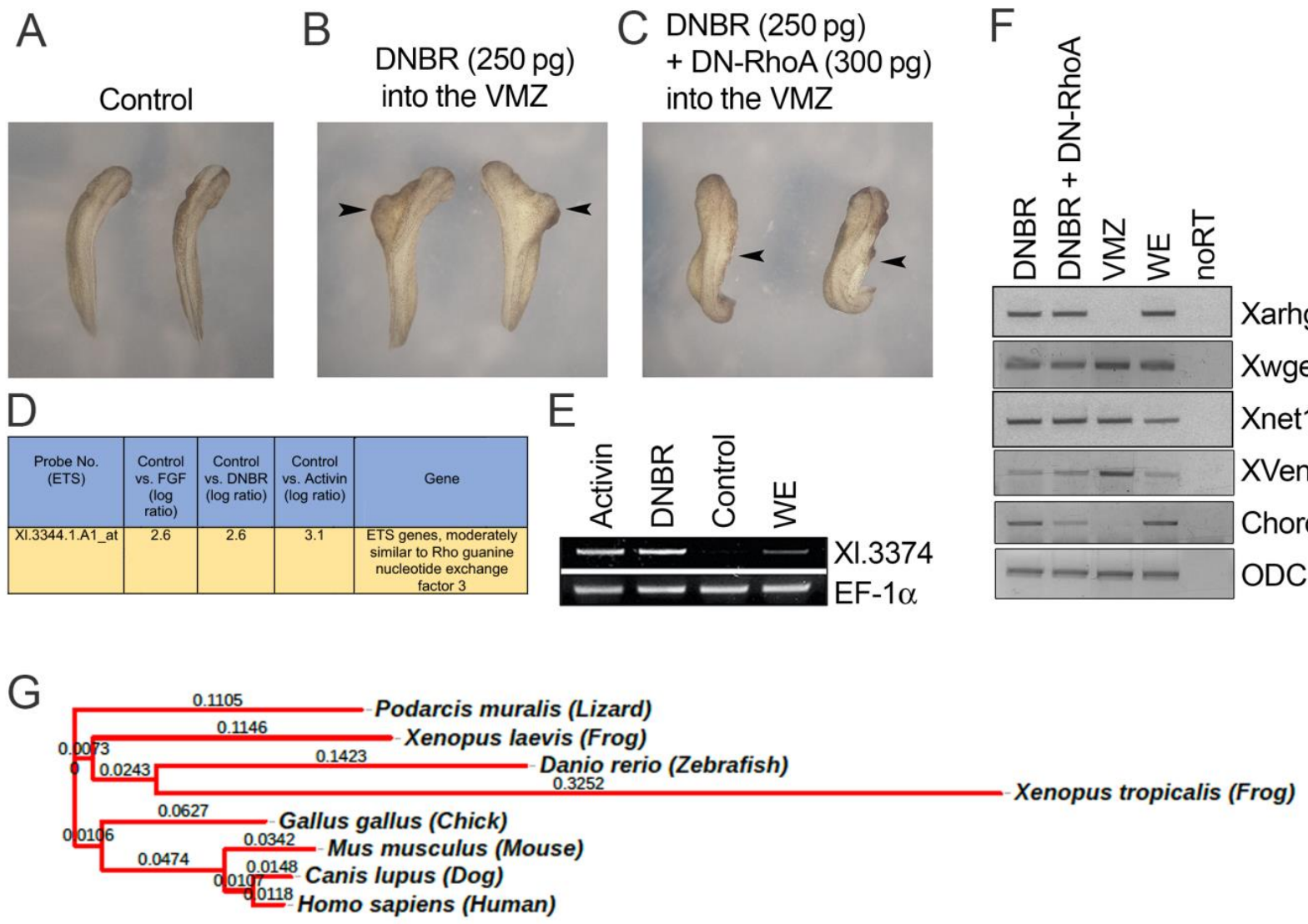

Figure 1. Bmp inhibition induced a secondary axis and requires RhoA activation of gastrulation cell movement in the VMZ. Identification of Xarhgef3.2. (A-C) The embryos were co-injected with $500 \mathrm{pg}$ of DNBR mRNA with or without $300 \mathrm{pg}$ of DN-RhoA at the four-cell stage into the VMZ. The noninjected control and injected embryos were analyzed at the 28-30 stage. (D) Microarray analysis data showed that X1.3374.1.1A_at is induced by DNBR (500 pg/embryo), activin ( $25 \mathrm{ng} / \mathrm{mL})$, and bFgf (100 ng/mL) at stage 11. (E) The microarray data were confirmed by RT-PCR at stage 11; EF-1a was used as a loading control. (F) The VMZ explants of the embryos $((\mathbf{A}-\mathbf{C})$ conditions) were dissected at stage 10. RT-PCR was performed to examine the expression pattern of the indicated genes at stage 12. (G) Phylogenetic tree created by amino acid sequence comparison of Xarhgef3.2 of the various species shown in the tree.

Activin and Fgf are well-known signal molecules that can promote elongation, mimicking the CE movement in the Xenopus AC system [44,46]. In contrast, overexpression of Bmp blocks activin-mediated elongation of ACs [11]. We assumed that the elongation behavior of ACs may be related to expression changes in the Wnt-PCP component genes. To identify factors of the Wnt-PCP pathway involved in BMP inhibition and activin/Fgf-mediated AC elongation (CE movement), three different conditions were assayed in the AC system, followed by profiling of the RNA transcripts isolated from the ACs (stage 11). The conditions were for samples treated either with activin $(25 \mathrm{ng} / \mathrm{mL}), \mathrm{bFgf}(100 \mathrm{ng} / \mathrm{mL})$, or those that were dissected from the DNBR-injected embryos ( $2 \mathrm{ng} / \mathrm{embryo}$ ). Microarray analysis was performed using RNA from DNBR-injected/activin/bFgf-treated ACs. Gene expression profiling was with a Xenopus Affymetrix Gene Chip containing 14,400 gene transcripts for identification of candidate genes. The candidate genes had expression increases under all three AC groups (Figure 1D plus Supplementary Tables). Upregulation of the candidate EST 'X1.3374.1.A1_at' was then confirmed via RT-PCR in RNA obtained from the ACs (stage 11) both for DNBR- (500 pg/embryo) and activin ( $50 \mathrm{ng} / \mathrm{mL}$ )-treated samples (Figure 1E). 
The cDNA of X1.3374.1.A1_at encoded Arhgef3.2, which is a Dbl family Rho GEF containing a Dbl homology (DH) domain (mediating GEF activity) and a pleckstrin homology (PH) domain (used for binding). Protein sequence analysis showed a high degree of sequence homology between the Xenopus and human versions (at 79.8\% identity) (Supplementary Figure S2), and we referred to the gene as Xarhgef3 (specifically, Xarhgef3.2.L). To examine whether Xarhgef3.2 expression and/or fate change of the VMZ cells were affected in the DNBR and DN-RhoA co-injection group, RT-PCR analysis was performed using the VMZ explants. DN-RhoA co-injection had no additional effects on RhoGEF expression, including for Xarhgef3.2 and known genes Xwgef and Xnet1. In addition, obvious cell fate change was not observed, as shown in Figure 1F. Notice that DN-RhoA co-injection still maintained the $\mathrm{DMZ}$ character with respect to chordin expression (compare the second lane with the third lane of the VMZ in Figure 1F and Supplementary Figure S1C). There was also robust Xarhgef3.2 expression, indicating that fate change may not be the main reason for the secondary partial axis loss in DN-RhoA- and DNBR-co-injected embryos. Finally, the Xarhgef3.2 protein was conserved, and we presented the phylogenetic tree (Figure 1G) created by amino acid sequence comparison of Xarhgef3.2 shown in Supplementary Figure S2. Altogether, Xenopus arhgef3.2 upregulation of ACs in both Bmp inhibition and activin-treated conditions suggested that Bmp signal gradient and CE movement may be interlinked through the transcription regulation of Xarhgef3.2.

\subsection{Xarhgef3.2 Is Predominantly Expressed in the DMZ at the Gastrula Stage}

Xarhgef3.2 was upregulated in the ACs by Bmp inhibition. During early normal gastrulation (around stage 10-11), Bmp is predominantly expressed in the VMZ and is inactivated in the DMZ $[47,48]$. To examine the inversed correlation between the Bmp gradient and the expression of Xarhgef3.2, both temporal and spatial expressions of Xarhgef3.2 were analyzed by RT-PCR. First, the temporal expression of Xarhgef3.2 was examined using RNA isolated from the whole embryos at successive developmental stages. Expression of Xarhgef3.2 was seen starting from the unfertilized egg and registered to be significantly elevated from stage 10 (the stage when CE begins) while being maintained until the tadpole stage of stage 24 (Figure 2A). The temporal and spatial expression patterns of Xarhgef3.2 were also determined using an in situ hybridization assay at different stages of Xenopus development. Previously, Hufton et al. reported that Xarhgef3.2 is expressed around the dorsal marginal zone or the dorsal lip during the early gastrula stage embryo [49]. Similarly, we found that Xarhgef3.2 expression is restricted in the dorsal organizer region. However, Xarhgef3.2 expression gradually shifted to the neural fold region and the prospective head region at a later stage (neurula- and tadpole-stage Xenopus) (Figure 2B, stage 24 and 28). To confirm whether the Bmp4 gradient was inversely correlated with the endogenous expression pattern of Xarhgef3.2, VMZs and DMZs were dissected from the normal embryos at stage 10. To examine the normal dissection of the DMZ and the VMZ, the chrd expression of the DMZ, gata2 of the VMZ, and $x b r a$ for pan-mesoderm specific markers were confirmed by RT-PCR (Figure 2C, lines 5-7). The expression of Xarhgef3.2 was predominantly found in the DMZ and much less in the VMZ (Figure 2C, line 1; compare lanes 1 and 2). The results confirmed the data from the in situ hybridization assay; Xarhgef3.2 was highly expressed in the dorsal region. On the other hand, previously, the expression levels of Xnet1 and Xwgef [27,28] were shown to be similar in the dorsal and ventral regions (Figure 2C, lines 2 and 3). The similar expression levels of net1 or Xwgef in the DMZ and the VMZ indicate that Xarhgef3.2 is a specific candidate molecule, possibly modulated by the BMP gradient during the early onset of gastrula movement. The subcellular localization of Xarhgef3.2 was further examined in the DMZ explants of the Xenopus embryos at stage 13. The characterized guanine nucleotide exchange factors such as Xwgef function with small GTPases in the plasma membrane [27]. Thus, cellular localization of Flag-tagged Xarhgef3.2 and HA-tagged RhoA was analyzed using immunostaining with an anti-Flag antibody. The results showed that Xarhgef3.2 was localized at the plasma membrane and colocalized with HA-tagged RhoA in the DMZ explants (Figure 2D). To rule out that the signal was not an autofluorescence ar- 
tifact, the localization of Xarhgef3.2 was examined in the control AC and the activin-treated AC cases. As expected, Xarhgef3.2 was localized in the nucleus of the untreated control ACs (Figure 2D) and at the plasma membrane in the elongated ACs with activin treatment (Figure 2D). These results suggest that Xarhgef3.2 in the DMZ is functionally active as localized in the plasma membrane during CE cell movement of early gastrula embryos. We then examined whether the BMP gradient could indeed modulate the expression of Xarhgef3.2 in the DMZ and the VMZ. According to our expectation, injection of bmp4 in the DMZ slightly reduced the expression of Xarhgef3.2 (Figure 2E, line 1; compare lanes 1 and 2). On the other hand, injection of DNBR at the VMZ resulted in upregulated arhgef3.2 expression (Figure 2E, line 1; compare lanes 3 and 4). In this experiment, some of the control markers including chrd (dorsal mesoderm, direct target of activin/Smad2,3 [50]), gata2 (or ventx1.1) (ventral mesoderm and direct target of BMP/Smad1 [51]), xbra (pan-mesoderm, Fgf target [52]), and wnt11 (wnt11b; noncanonical wnt) were shared as shown in Figure 1C to confirm gain and loss of function for BMP reversing the dorsoventral character of the cells while the mesoderm character was maintained. Taken together, the results suggest that Bmp gradient and the expression pattern of Xarhgef3.2 are inversely correlated, and the Xarhgef3.2 temporal expression pattern with its cellular localization in the DMZ also depicts an active function for Arhgef3.2 in gastrulation movement.
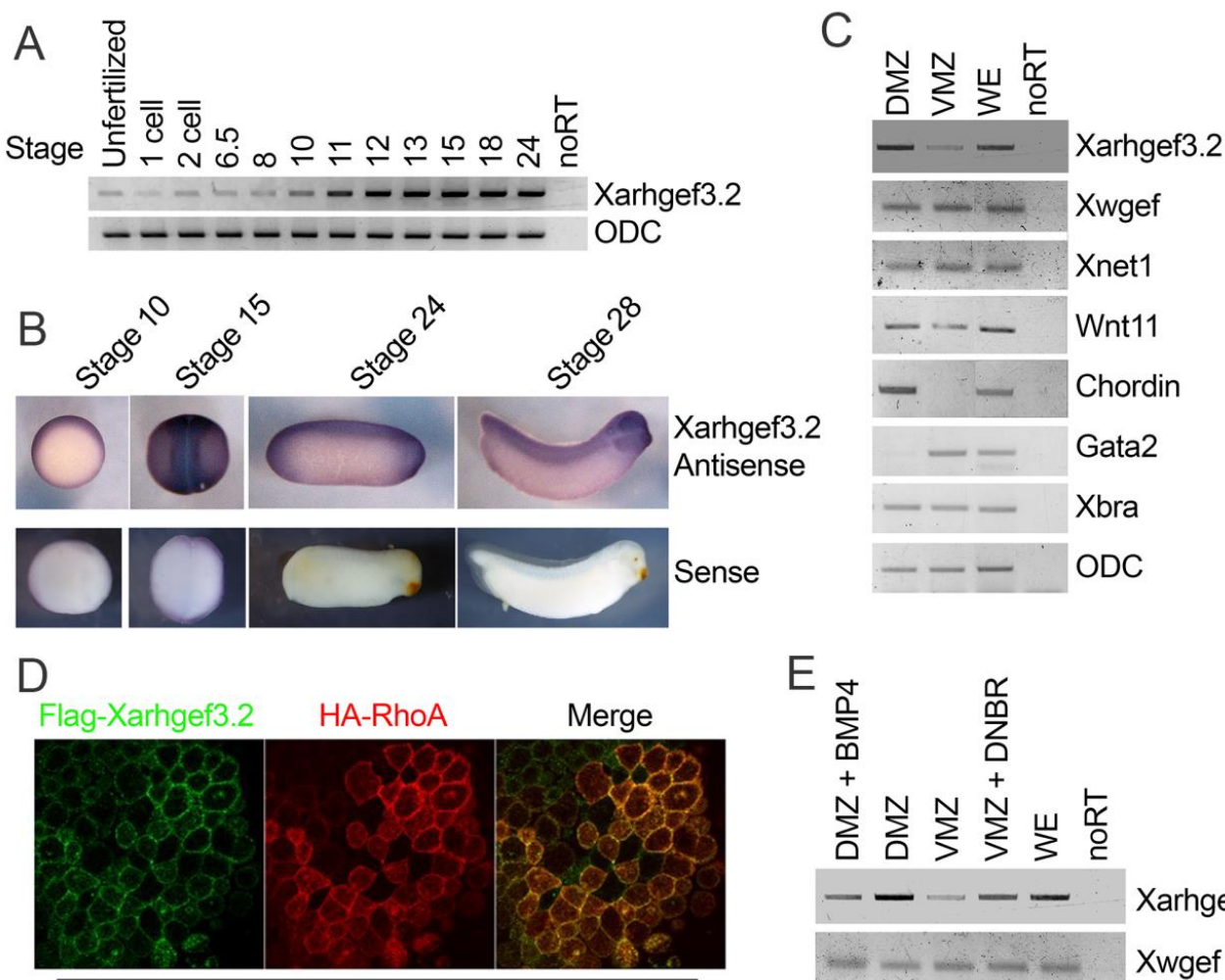

DMZ explants
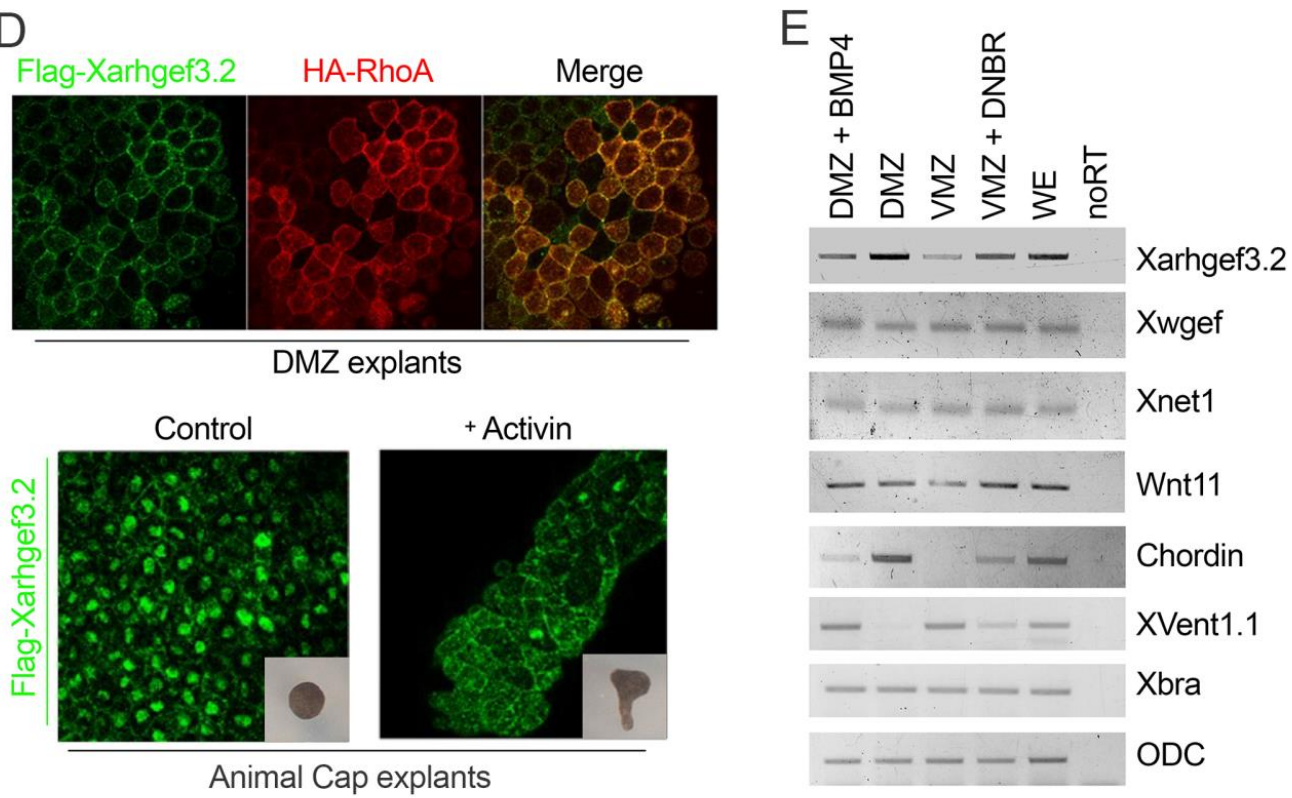

Figure 2. Xarhgef3.2 is expressed in the DMZ at the gastrula stage. (A) Temporal expression pattern 
of Xarhgef3.2 was analyzed using RT-PCR at various developmental stages as indicated. (B) Spatial expression of Xarhgef3.2 was analyzed using whole mount in situ hybridization at the indicated stages. Stage 10: vegetal view, dorsal lip on top; stage 15: dorsal view; stages 20 and 28: lateral views. (C) RT-PCR confirmed the spatial expression pattern of the indicated gene expression by using each dissected (at stage 10) region of the embryo at stage 12. (D) RNAs of Flag-Xarhgef3.2 (100 pg/embryo) and HA-RhoA (100 pg/embryo) were co-injected into the dorsal marginal zone at the four-cell stage. The DMZ explants were dissected at stage 10 and fixed using MEMFA and stained with the anti-Flag and anti-HA antibodies. Localization of Flag-Xarhgef3.2 was analyzed with the DMZ explants using confocal microscopy. (E) The BMP4- or DNBR-injected DMZ or VMZ explants were examined using RT-PCR to analyze the expression level of the indicated genes at stage 12 (ventral marker: gata2 and ventx1.1; mesoderm marker: $x b r a$; organizer marker: chrd; loading control: odc).

\subsection{Overexpression of Xarhgef3.2 Modulates Gastrulation without Affecting the Cell Fate}

To examine the functional role of Xarhgef3.2 in the early development of Xenopus, we performed gain-of-function assays in which the animal pole or dorsal blastomeres of the embryos were injected with mRNA encoding full-length Xarhgef3.2 at the one-cell or four-cell stages. The embryos were observed for their morphological changes at stage 28 . Ectopic expression of Xarhgef3.2 in the animal pole region led to gastrulation defects in the whole embryos in a dose-dependent manner with the percentage of gastrulation-defective embryos increasing with a higher-dose injection of Xarhgef3.2 mRNA (Figure 3). The embryos injected with Xarhgef3.2 into each of the two dorsal blastomeres ( $25 \mathrm{pg} / \mathrm{blastomere})$ at the four-cell stage resulted in remarkably reduced anterior structures with severely defective gastrulation (Figure 3A). The resultant morphologies implicate that overexpression of Xarhgef3.2 may affect the cell movement of embryo gastrulation. To examine whether the gastrulation defect was caused by the GDP-GTP exchange activity of Xarhgef3.2, we cloned a mutant construct of Flag-Xarhgef3.2 (L269E) which loses the GDP-GTP exchange activity $[53,54]$. The gradually increased amounts of mRNA $(10,50$, and $100 \mathrm{pg} / \mathrm{embryo})$ of wt (wild-type)-Flag-Xarhgef3.2 or mt (mutant)-Flag-Xarhgef3.2 (L269E) were injected into one-cell embryos and the phenotypic changes were analyzed at stage 28 . The increased amount of the WT-Xarhgef3.2 injection led to the proportionally increased gastrulation defects (Figure 3B: left-side graph). However, the ectopic expression of Xarhgef3.2 (L269E) (up to $100 \mathrm{pg} /$ embryo) did not induce any gastrulation defects and hence suggested that the gastrulation defect caused by overexpression of Xarhgef3.2 may depend on its GDP-GTP exchange activity (Figure 3B). To confirm protein expression of the injected mRNAs for the Flagged versions, the proteins were detected from the embryos using an anti-Flag antibody (Figure 3C). The similar experiment using WT-Xarhgef3.2 and the Xarhgef3.2 (L269E) mutant was performed to rescue Xarhgef3.2 knockout cells by You et al. (2021) [53]. We further eliminated the possibility that gastrulation might be impaired due to a change in gene expression. RT-PCR was performed to analyze gene expression using the ACs injected with WT-Xarhgef3.2 mRNA. As shown in Figure 3D, overexpression of Xarhgef3.2 did not change the expression patterns of dorsal mesodermal genes of the organizer for goosecoid $(g s c)$ and chrd, the pan-mesodermal gene $x b r a$, and the endodermal gene mixer expression in the ACs at stage 13. Collectively, these data emphasize that Xarhgef3.2 overexpression impaired normal gastrulation whose defective function may depend on its GDP-GTP exchange activity without affecting cell fate determination. 
A

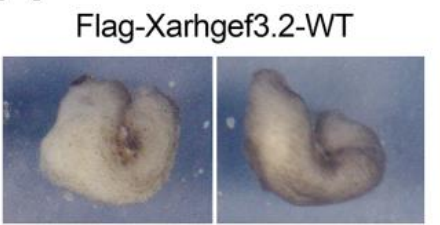

Flag-Xarhgef3.2-L269E

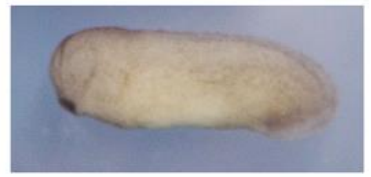

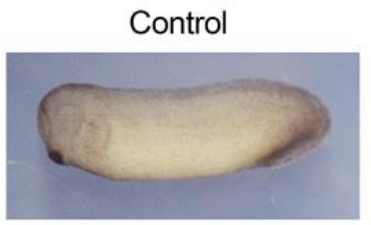

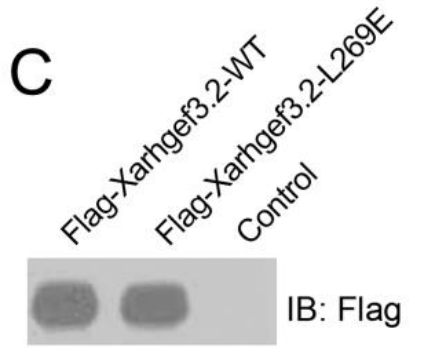

IB: $\beta$-Actin
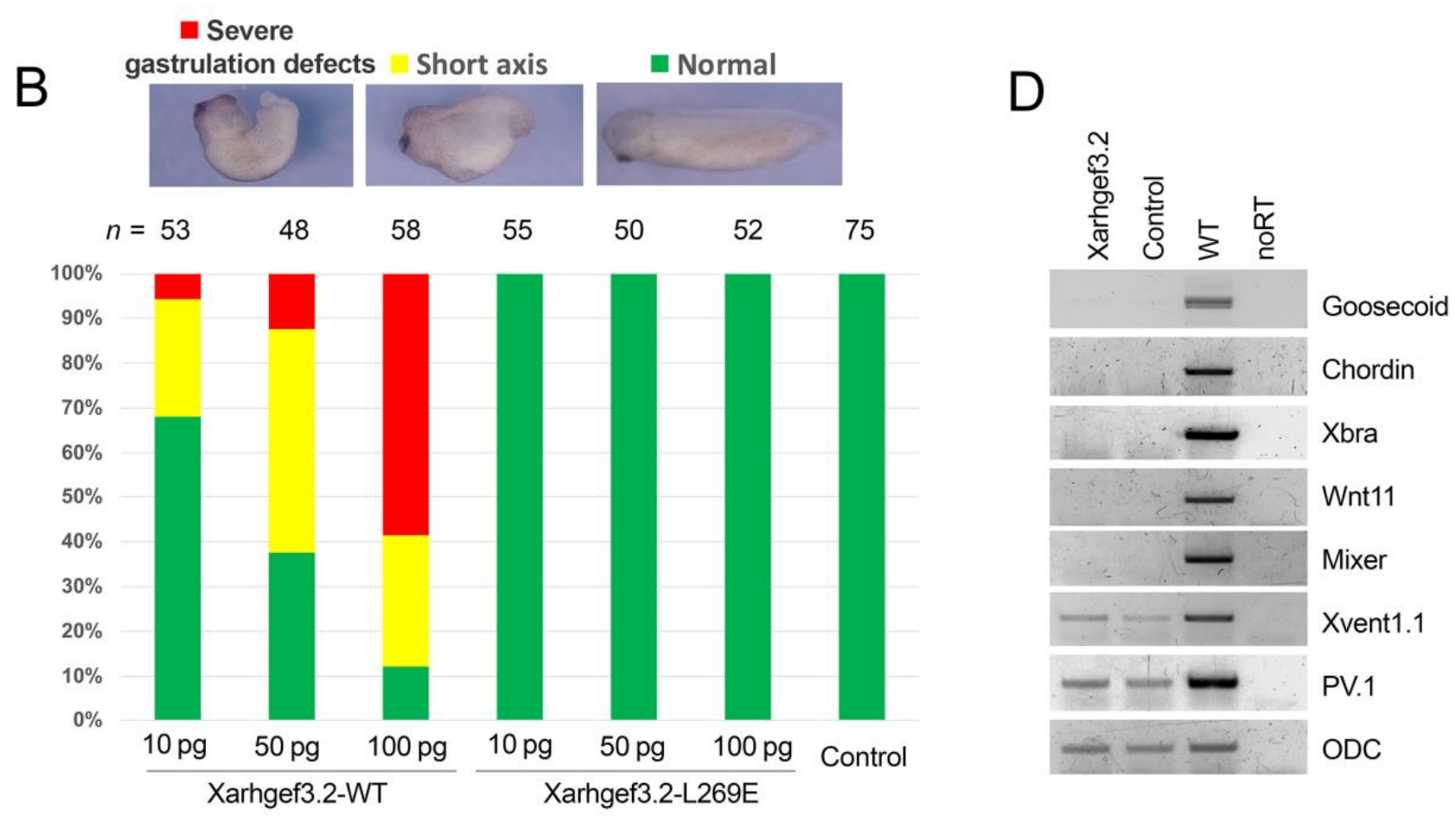

Figure 3. Overexpressed Xarhgef3.2 induces gastrulation defects of Xenopus embryos. (A) RNAs of WT-Xarhgef3.2 or MT-Xarhgef3.2 (L269E) were injected into the animal pole region at the one-cell stage (100 pg/embryo). (B) RNAs of Flag-Xarhgef3.2 (100 pg/embryo) or Flag-Xarhgef3.2 (L269E) (100 pg/embryo) were injected at the one-cell stage. Phenotypes were evaluated as indicated at stage 28. (C) The expression level of each Flag-tagged construct was confirmed by Western blot analysis. (D) ACs were dissected from the Xarhgef3.2 (100 pg/embryo)-injected embryos. The explants were incubated until stage 13, and RT-PCR was performed for analysis of the indicated gene expression.

\subsection{Xarhgef3.2 Is Required for Normal Gastrulation of Xenopus Embryos}

To examine the functional requirement of Xarhgef3.2, a loss-of-function study was performed with antisense morpholino oligos targeting the endogenous Xarhgef3.2 mRNA. Oligos target the 5'UTR region of Xarhgef3.2 mRNA (Figure 4A). The inhibitory activity of the Xarhgef3.2 morpholino oligo (MO) was evaluated with Western blot analysis by comparing the affected protein levels of the 5'UTR-Xarhgef3.2-3Flag construct containing the $5^{\prime}$ UTR region which includes the MO target sequence. In addition, 3Flag was tagged in the $3^{\prime}$ region for detection of the protein without protection of the $\mathrm{MO}$ action. The MO was confirmed to block translation of the target gene $5^{\prime}$ UTR-Xarhgef3.2-3Flag without affecting amounts of the endogenous Xarhgef3.2 RNA (compare the first lane with the third lane of line 1 (stage 12) in Supplementary Figure S1C) and control protein actin as shown in Figure 4A (second line). Phenotypic changes were then observed by injecting the Xarhgef3.2 MO. MO injection into the animal pole region at the one-cell stage (60 ng/embryo) led to axis shortening with a mild gastrulation defect in the whole embryos. Injection of the 
Xarhgef3.2 MO into the marginal zone region of two dorsal blastomeres ( $15 \mathrm{ng} /$ blastomere) at the four-cell stage resulted in an abnormal head structure and severe gastrulation defects (Figure 4B; dorsal marginal zone). However, when the same amount of the MO (15 ng/blastomere) was injected into the ventral marginal zone, no severe gastrulation defects were observed (Figure 4B; ventral marginal zone). The Control MO also did not cause any severe phenotypic changes in the whole embryos (Figure 4B; control). Differential severity of the gastrulation defect suggests that the endogenous function of Xarhgef3.2 is required for normal gastrulation and a specific role in the dorsal mesoderm during gastrulation of Xenopus embryos. To confirm whether the gastrulation defect caused by the Xarhgef3.2 MO specifically depended on injection of the MO, the morphological changes were compared in three different RNA-injected groups: (1) Flag-Xarhgef3.2 alone, (2) Xarhgef3.2 MO alone, and (3) co-injection of Flag-Xarhgef3.2 and the MO together. The phenotypic changes were observed at stage 28. Co-injection with RNAs of Flag-Xarhgef3.2 and the Xarhgef3.2 MO (group 3) rescued the more severe gastrulation defects found either with Flag-Xarhgef3.2 alone (group 1) or the Xarhgef3.2 MO alone (group 2) (Figure 4C). Since the MO targeted the $5^{\prime}$-UTR region of Xarhgef3.2, a rescue experiment was performed using $5^{\prime}$ Flag-Xarhgef3.2 which does not contain the $5^{\prime}$-UTR region of the Xarhgef3.2 target sequence of the MO (compare the first lane with the second and third lanes of protein bands in Figure 4C). The results indicate that proper activity of Xarhgef3.2 is necessary for normal CE movement of gastrula embryos. We then performed AC elongation assays using the Xarhgef3.2 MO. Activin treatment can instigate elongation accompanying active cell migration and CE movement in the AC system of Xenopus embryos [44,55]. Xarhgef3.2 MO injection resulted in effective reduction of the elongation found in the activin $(50 \mathrm{ng} / \mathrm{mL})$ treated ACs (Figure 4D). Although certain changes in the markers were observable, we repeatedly found that the cell fate was not affected much by the Xarhgef3.2 MO which was confirmed by RT-PCR at stage 11 and stage 24 (Figure 4E, stage 11, and Figure 4F, stage 24). The results of the AC assay further support the view that Xarhgef3.2 is necessary for CE of Xenopus embryos. Together, loss-of-function studies for Xarhgef3.2 suggested that Xarhgef3.2 is an essential molecule necessary for gastrulation cell movement which is functionally more active in the DMZ of gastrula embryos. 

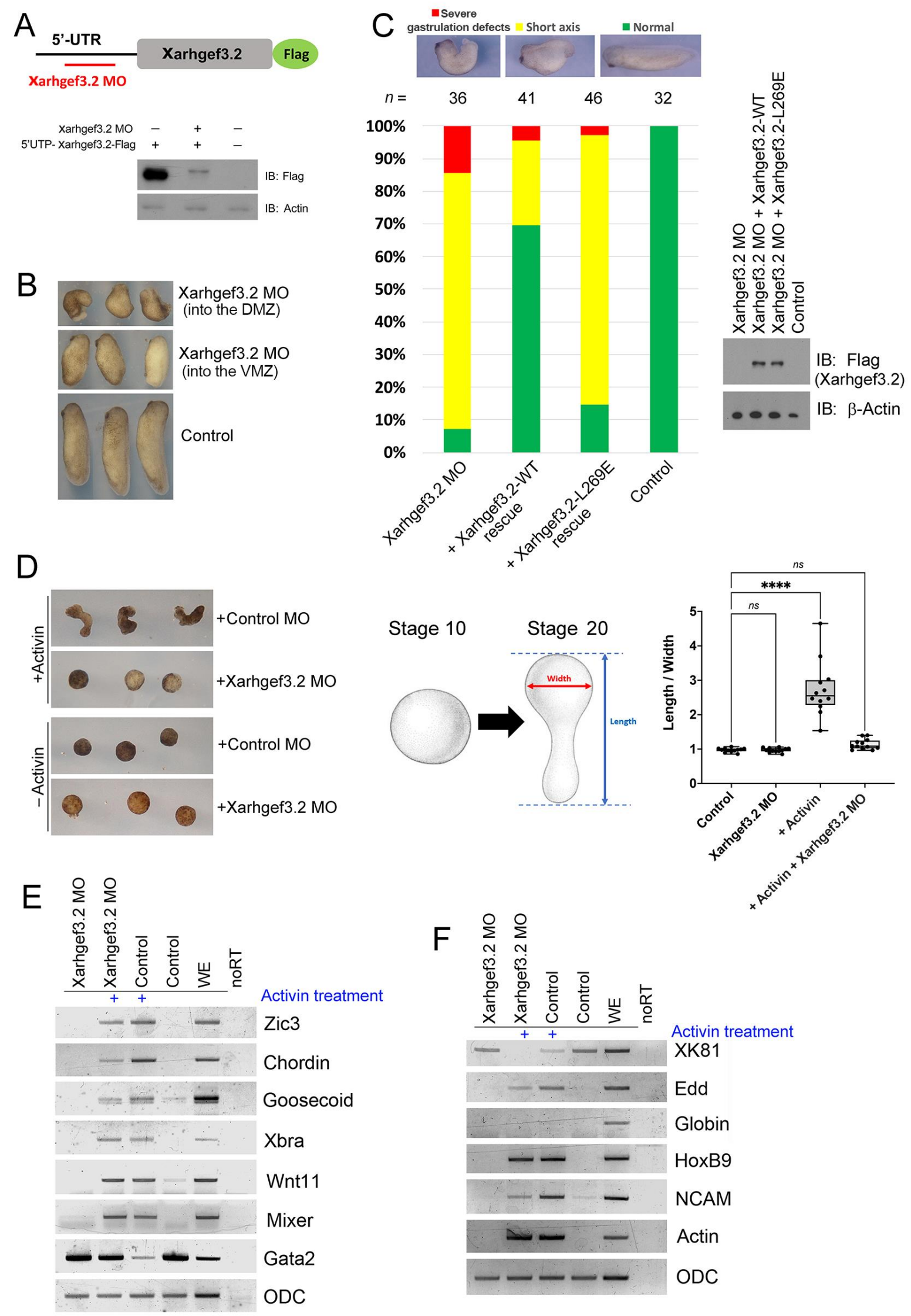

Figure 4. Knockdown of Xarhgef3.2 leads to a gastrulation defect without affecting the cell fate. 
(A) The whole embryos were injected with RNAs of the 5'UTR-Xarhgef3.2-3Flag construct (100 pg/embryo) along with the Xarhgef3.2 MO (60 ng/embryo) as indicated. The embryos were used for Western blot check of specific knockdown of Xarhgef3. (B) The Xarhgef3.2.L MO was injected into the animal pole region at the one-cell stage ( $60 \mathrm{ng} / \mathrm{embryo})$ or into two blastomeres of both the dorsal and ventral marginal zone at the four-cell stage (15 $\mathrm{ng} /$ blastomere). The morphological changes of the embryos were then examined at stage 28. (C) RNAs of Flag-Xarhgef3.2 (50 pg/embryo; an off-target construct against the MO) or the Xarhgef3.2 MO (60 ng/embryo) were injected to the one-cell stage embryos. Phenotypes were evaluated as indicated at stage 28. (D) The ACs injected with the MO of Xarhgef3.2 were dissected at stage 8 and incubated with activin $(50 \mathrm{ng} / \mathrm{mL})$. Phenotypes of the ACs were evaluated at stage 16. The histogram depicts the width/length ratio of the animal cap explants. Quantification with one-way ANOVA, scatterplots represent the means \pm SD from three biological repeats. Dunn's multiple comparison, ${ }^{* * * *} p<0.0001$, ns -no statistical differences between the groups. (E,F) The ACs injected with the MO of Xarhgef3.2 were dissected at stage 8 and incubated in the presence or absence of activin $(50 \mathrm{ng} / \mathrm{mL})$ until stages 11 (E) and 24 (F). RT-PCR was performed for analysis of the indicated gene expressions.

\subsection{Xarhgef3.2 Specifically Interacts with RhoA and Regulates CE Cell Movement through Modulation of Noncanonical Wnt Signaling}

Gastrulation movement of Xenopus embryos is explicitly regulated by noncanonical Wnt-PCP signaling [56] and RhoA functions at the downstream target of this pathway [24]. As shown by subcellular localization and gain-of-function assays of Xarhgef3.2 with the affected CE cell movement of the dorsal marginal zone, we assume that Xarhgef3.2 functions as a component of the Wnt-PCP signal cascade and interacts with RhoA. Having insight into the specificity of Rho family GEFs is important for understanding the biological roles of these proteins; we thus examined whether this interaction was limited to RhoA or if there were other small GTP-binding proteins of the Wnt-PCP pathway, Rac1 and Cdc42, that were also involved. A prolonged activation of RhoA via a constitutively active mutant of RhoA leads to gastrulation defects [22,45], and previous studies reported that human Arhgef3 activates RhoA only but not Rac1 and Cdc42 [30]. We examined the specificity of Xarhgef3.2 by carrying out an RBD (Rho-binding domain) pulldown assay using the DMZ explants injected with the Xarhgef3.2 mRNA or Xarhgef3.2 MO. Since RBD is known to bind only to GTP-bound active RhoA [29], the band intensity of the RBD-bound RhoA is proportional to the amount of active RhoA. Ectopic expression of Xarhgef3.2 enhanced RhoA activity, and injection of the Xarhgef3.2 MO reduced the RhoA activity (Figure 5A). In contrast, the Rac1 or Cdc42 (p21)-binding domain (PBD) pulldown assay demonstrated that the activities of Rac1 or Cdc42 were not changed by overexpression or knockdown of Xarhgef3.2 (Figure 5B). Thus, we conclude the interaction of Xenopus Arhgef3.2 is limited only to RhoA. 

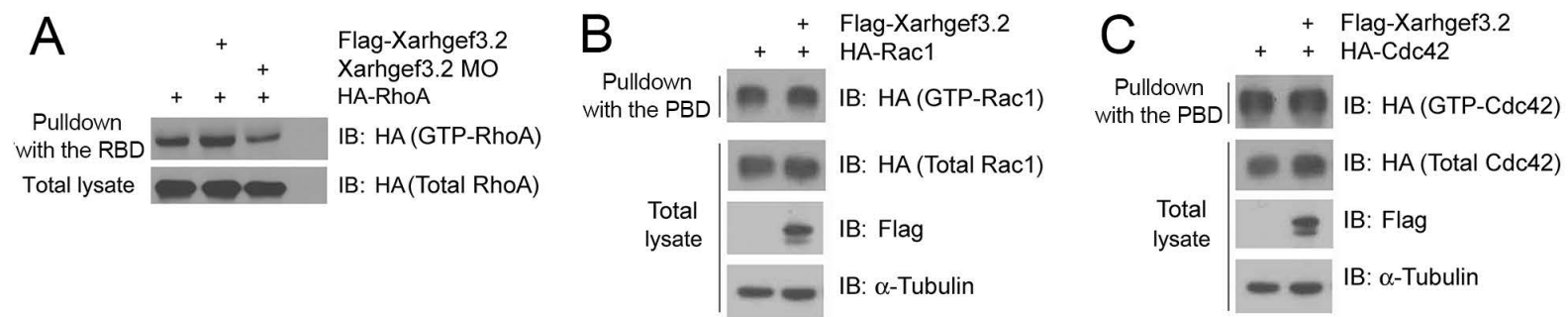

D

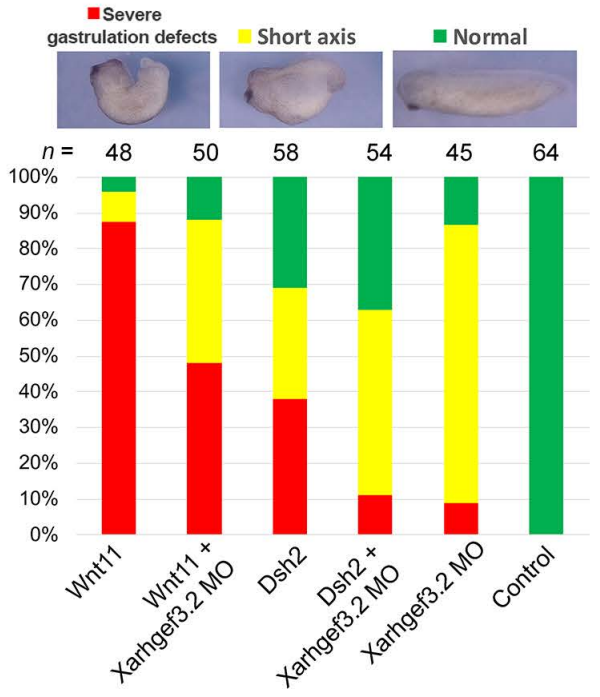

F

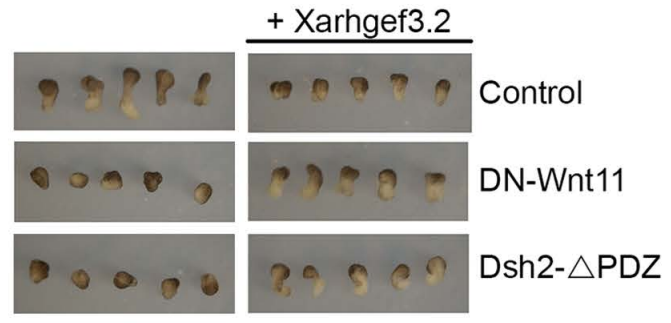

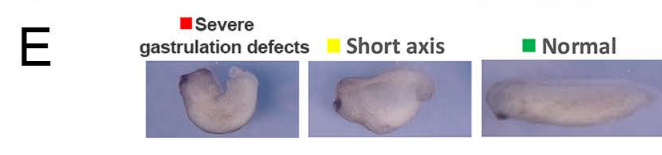
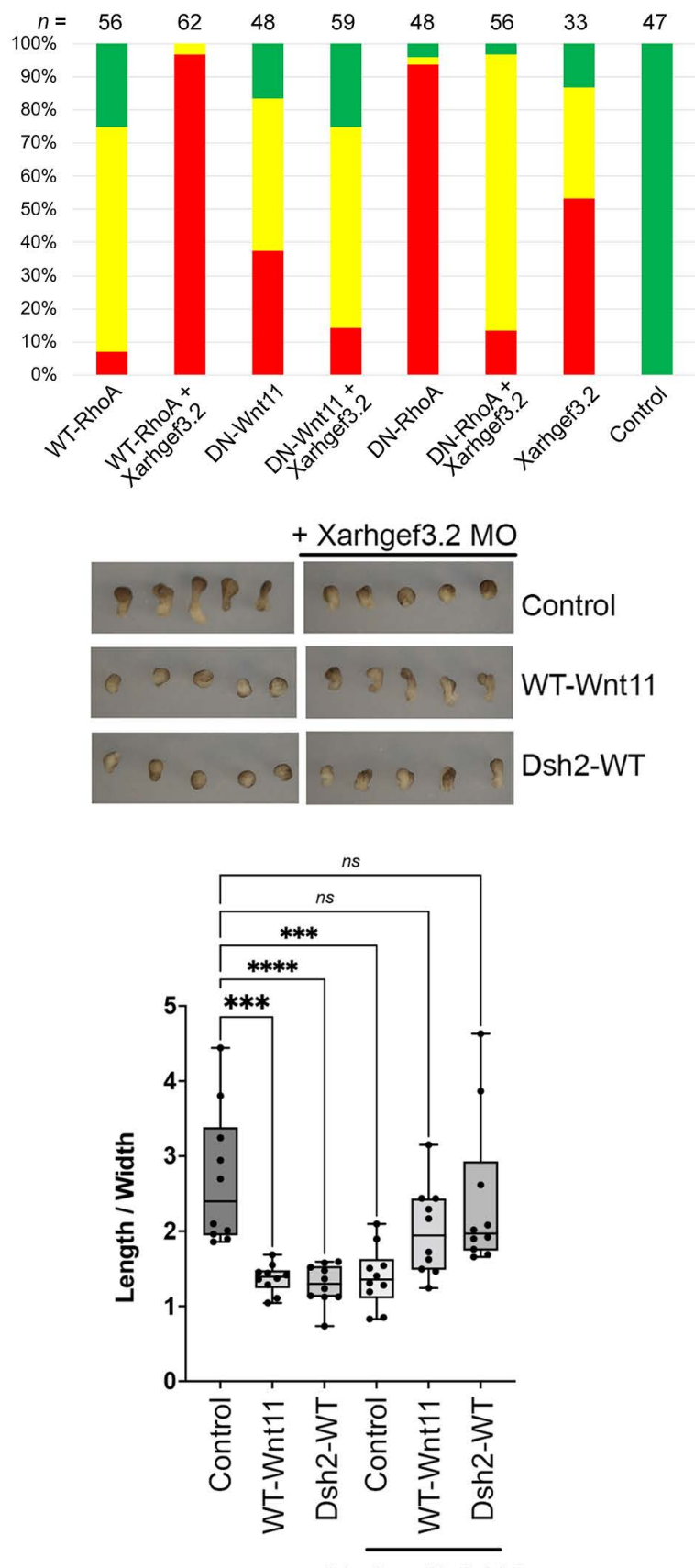

+ Xarhgef3.2 MO

Figure 5. Xarhgef3.2 regulates CE movement in a noncanonical Wnt signal cascade. (A) The DMZ explants injected with Xarhgef3.2 into the dorsal marginal zone at the four-cell stage ( $25 \mathrm{pg} /$ blastomere) 
or the Xarhgef3.2 MO (15 ng/blastomere) were dissected at stage 10. Rho-binding domain (rhotekin, RBD) pulldown assay was performed for the analysis of RhoA activity. (B,C) The DMZ explants injected with Xarhgef3.2 into the dorsal marginal zone at the four-cell stage ( $25 \mathrm{pg} /$ blastomere) were dissected at stage 10. The Rac1- or Cdc42 (p21)-binding domain (PAK1, PBD) pulldown assay was performed for the analysis of Rac1 or Cdc42 activity. (D) WT-Wnt11 (1 ng) or WT-Dsh2 (1 ng) RNAs were injected singly or co-injected with the Xarhgef3.2 MO $(60 \mathrm{ng})$ into the animal pole region at the one-cell stage. Phenotypes were evaluated as indicated at stage 28. (E) WT-RhoA (500 pg), DN-wnt11 (1 ng), and DN-RhoA (500 pg) RNAs were injected singly or co-injected with the Xarhgef3.2 RNA $(100 \mathrm{pg})$ into the animal pole region at the one-cell stage embryos. Phenotypes were evaluated as indicated at stage 28. (F) The DMZ explants injected with RNAs and the Xarhgef3.2 MO as indicated were dissected at stage 10 and incubated until stage 16 . The histogram depicts the width/length ratio of the Keller explants. Quantification with one-way ANOVA, scatterplots represent the means \pm SD from three biological repeats. Dunn's multiple comparison, ${ }^{* * *} p<0.001,{ }^{* * *} p<0.0001, n s-$ no statistical differences between the groups.

We also performed an epistatic analysis with Wnt-PCP components, Wnt 11, Dsh2, that are known to modulate noncanonical Wnt signaling in order to further validate our assumptions. Ectopic expression of WT-Wnt11 or WT-Dsh2 induced gastrulation defects in the whole embryos, but co-injection with the Xarhgef3.2 MO rescued the phenotypic defects (Figure 5D). Gastrulation defects caused by injection with the mRNA of RhoA was significantly increased with co-injection with the Xarhgef3.2 RNA. The whole embryos injected with the mRNAs of $D N-w n t 11$ or $D N-R h o A$ also resulted in gastrulation defects, but co-injection with the mRNAs of Xarhgef3.2 decreased the phenotypic defects (Figure 5E). Our hypothesis was also substantiated using Keller explants. Ectopic expression of WTWnt11, DN-Wnt11, or WT-Dsh2 caused a reduction of elongation in the Keller explants compared to the control. However, co-injection with the mRNAs of Xarhgef3.2 or the Xarhgef3.2 MO rescued the reduced elongation (Figure 5F, also see the Keller explant pictures and the statistical measurement data of elongation). Together, these data suggest that Xarhgef3.2 may function as a regulatory component downstream of Wnt-PCP signaling and controls CE movement by specifically activating RhoA.

\subsection{N-Terminal Region of Xarhgef3.2 Interacts with Dsh2 through Daam1 under the Wnt-PCP Signaling Stimulation}

Our in vivo experiments illustrate that Xarhgef3.2 functions in the induction of RhoA in response to Wnt signaling. RhoA acts as a downstream target of noncanonical Wnt signaling by associating with Disheveled (XDsh2), and this association is interceded by Daam1 [24]. Our data showed that Xarhgef3.2 may act as a downstream component of noncanonical Wnt signaling in the DMZ. To gain more information about the mechanism of Xarhgef3.2 function, we performed biochemical studies with Dsh2 and Daam1, known vital components of noncanonical Wnt signaling [24,57]. We generated various mutant constructs containing each domain of Dsh2 as indicated in Figure 6A. Then, coimmunoprecipitation assays were performed between Xarhgef3.2 and Dsh2, and they showed that the PDZ and DEP domains of Dsh2 interact with Xarhgef3.2 (Figure 6B,C). To identify the portion of Xarhgef3.2 interacting with Dsh2, we performed coimmunoprecipitation assays with deletion mutants of Xarhgef3.2 as indicated (Figure 6D). The results show that the N-terminal of Xarhgef3.2 is bound to Dsh2 (Figure 6E). In addition, IP with serial deletion mutants of Xarhgef3.2 showed that the most N-terminal region of Xarhgef3.2 is required for the interaction with Dsh2 (Supplementary Figure S3A,B). We also showed that the nuclear localization signal (NLS) deletion mutants $(\rho \mathrm{N} 3)$ were predominantly localized at the plasma membrane. However, the Xarhgef3.2- $\rho \mathrm{N} 3$ mutant did not interact with Dsh2. (Supplementary Figure S3B,C). We then investigated whether the interaction between Xarhgef3.2 and Dsh2 increased under upregulation of Wnt-PCP signaling. Ectopic expression of Wnt11 increased binding between Xarhgef3.2 and Dsh2, but not with wnt8, a typical form of canonical Wnt, as it decreased this interaction (Figure 7A,B). Furthermore, we examined the interaction between Xarhgef3.2 and Daam1 as Daam1 binds to the PDZ and the 
DEP domain of Dsh2 [24], and the Xwgef N-terminal region interacts with Daam1 [27]. We found Xarhgef3.2 was immunoprecipitated with WT-Daam1 or N-Daam1 through the Nterminal part of Xarhgef3.2 (Figure 7C,D). Interaction between Xarhgef3.2 and Dsh2 in the presence of excessive N-Daam1 was analyzed to see whether the interaction of Xarhgef3.2 with Dsh2 was mediated by Daam1. Overexpression of N-Daam1 reduced the interaction between Xarhgef3.2 and Dsh2 (Figure 7E). These results suggested that Xarhgef3.2 may interact with Dsh2 through Daam1. We also examined colocalization of Xarhgef3.2 and Dsh2 or Xarhgef3.2 and Daam1. As shown, Xarhgef3.2 colocalized with Dsh2 and Daam1 at the plasma membrane in the DMZ explants (Supplementary Figure S4).
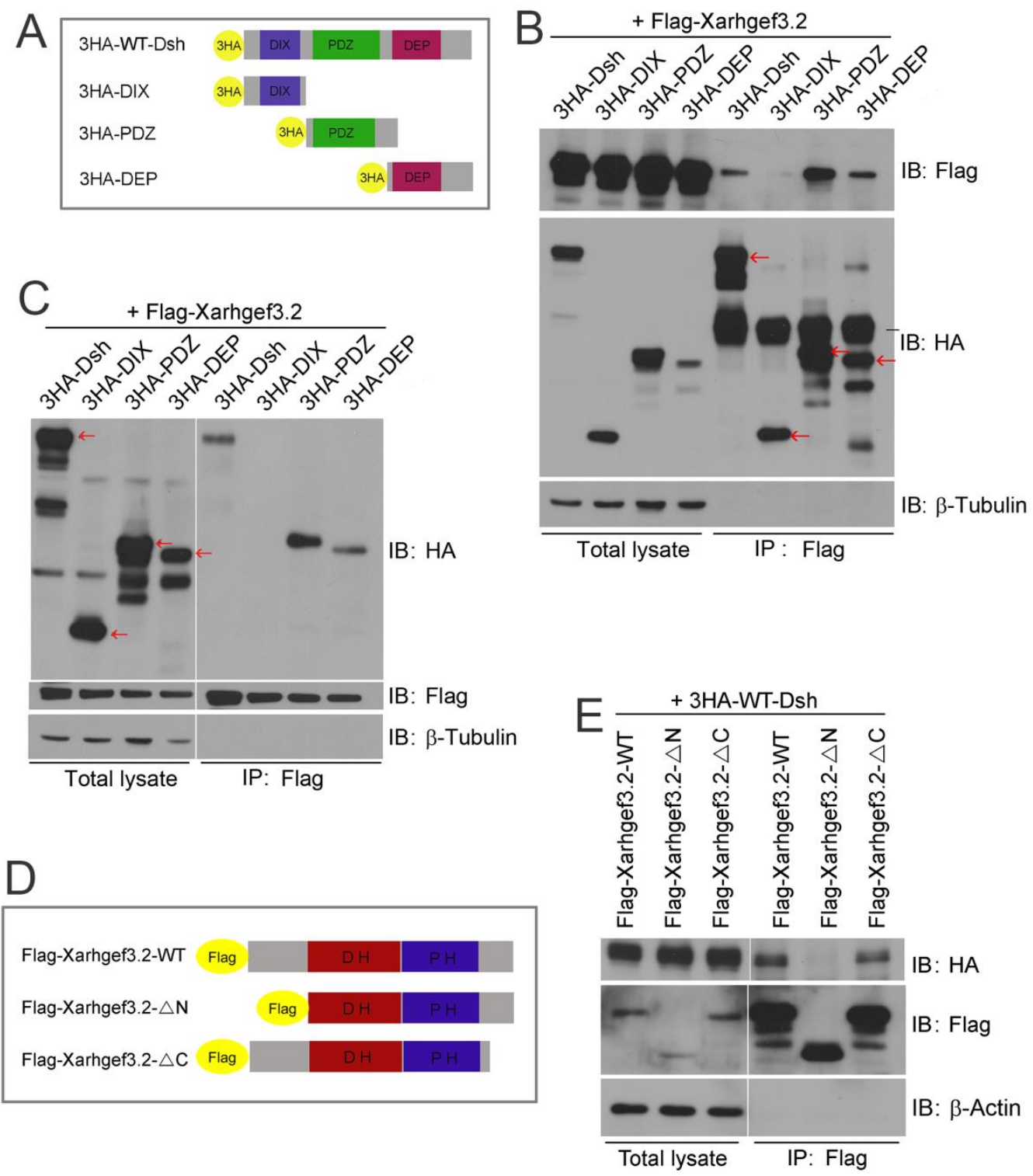

Figure 6. N-terminal region of Xarhgef3.2 is required for interaction with the PDZ and the DEP domain of Dsh2. (A) Schematic representation of HA-tagged constructs for Dsh2. (B,C) RNAs of Flag-Xarhgef3.2 (100 pg) were co-injected with HA-WT-Dsh2 (1 ng), HA-PDZ (1 ng), or HA-DEP $(1 \mathrm{ng})$ at the one-cell stage. Immunoprecipitation assays were performed with an anti-Flag antibody or an anti-HA antibody at stage 10. The red arrows indicate intact protein bands. (D) Schematic representation of Flag-tagged constructs of Xarhgef3.2. (E) RNAs of HA-WT-Dsh2 (1 ng) were coinjected with Flag-WT-Xarhgef3.2, Flag- $\rho N$ - Xarhgef3.2, or Flag- $\rho$ C-Xarhgef3.2 (each, 100 pg) at the one-cell stage. Immunoprecipitation assays were performed with an anti-HA antibody at stage 10. 

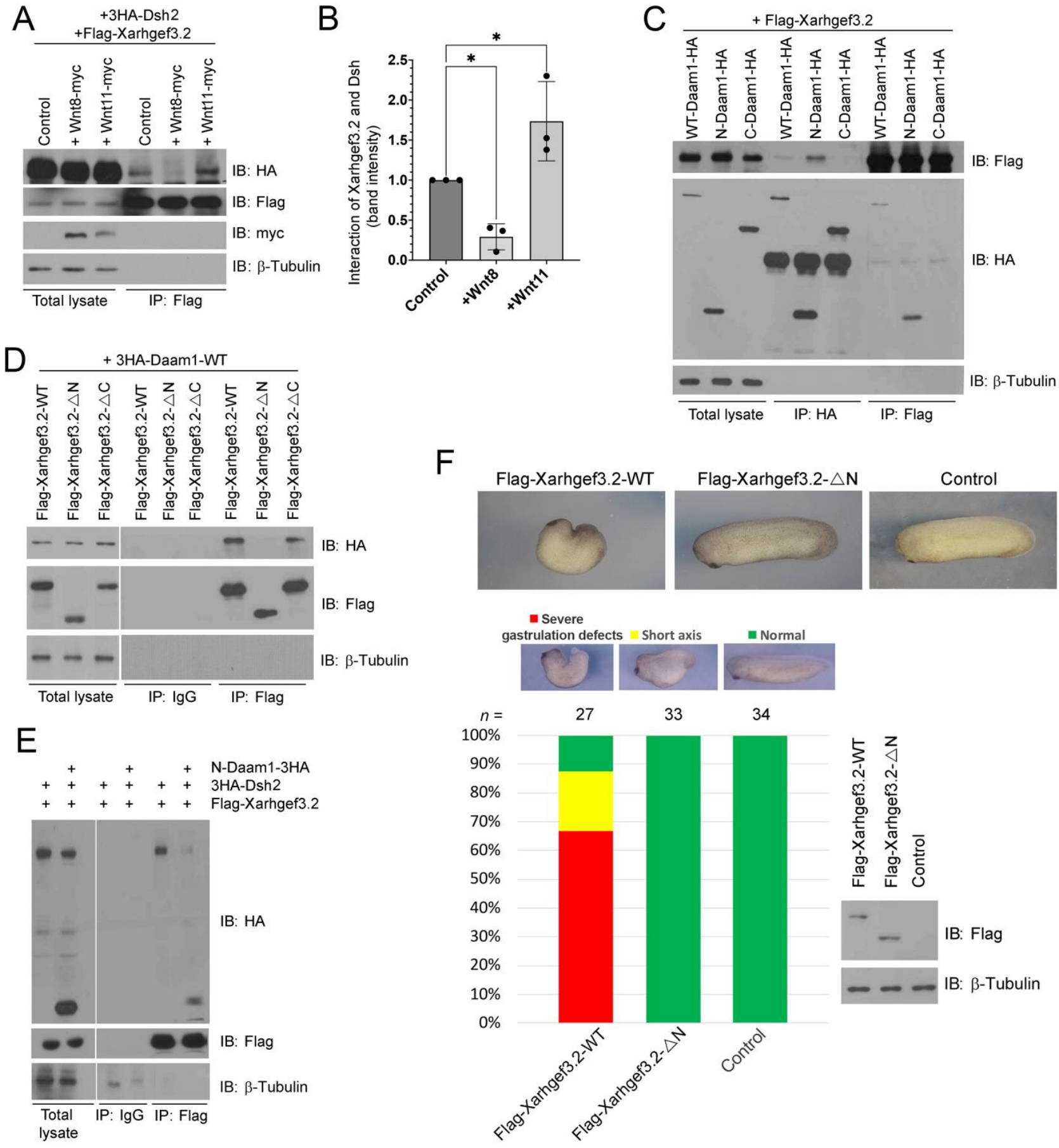

Figure 7. Xarhgef3.2 regulates gastrulation cell movements through interacting with noncanonical Wnt signaling components. (A) RNAs of Flag-Xarhgef3.2 (100 pg) and HA-Dsh2 (1 ng) were co-injected with wnt8-myc (500 pg) or wnt11-myc (500 pg) at the one-cell stage. Immunoprecipitation assay was performed with an anti-Flag antibody at stage 10. (B) The graph indicates the relative interaction level between Flag-Xarhgef3.2 and HA-Dsh2. Quantification with one-way ANOVA, scatterplots with bar represent the means $\pm \mathrm{SD}$ from three biological repeats. Dunn's multiple comparison, * $p<0.05$. (C) RNAs of Flag-Xarhgef3.2 (100 pg) were co-injected with HA-WT-daam1, HA-N-daam1, or $H A$-c-daam 1 (each, $1 \mathrm{ng}$ ) at the one-cell stage. Immunoprecipitation was performed with an anti-Flag antibody or an anti-HA antibody at stage 10. (D) RNAs of HA-WT-daam1 (1 ng) were co-injected with Flag-WT-Xarhgef3.2, Flag- $\rho N$-Xarhgef3.2, or Flag- $\rho C$-Xarhgef3.2 (each, 100 pg) at the one-cell stage. Immunoprecipitation assay was performed with an anti-HA antibody at stage 10. (E) RNAs 
of Flag-Xarhgef3.2 (100 pg) and HA-Dsh2 (1 ng) were injected or co-injected with HA-N-daam1 (2 ng) at the one-cell stage. Immunoprecipitation was performed with an anti-Flag antibody at stage 10 . (F) RNAs of Flag-Xarhgef3.2 (100 pg) or Flag- $\rho$ C-Xarhgef3.2 (100 pg) were injected at the one-cell stage. Phenotypes were evaluated as indicated at stage 28 . The expression level of each construct was confirmed by Western blot analysis.

We next describe the physical interaction of Xarhgef3.2 with Dsh2 and Daam1 by observing phenotypic changes in the whole embryos injected with the RNAs for FlagWT-Xarhgef3.2 or Flag- $\rho \mathrm{N}$-Xarhgef3.2 (Figure $6 \mathrm{D}$; N-terminal domain (including the NLS domain) deleted construct), with products that do not bind with Daam1. Overexpressing Flag- $\rho \mathrm{N}$-Xarhgef3.2 produced a phenotype similar to the phenotype observed in the control whole embryos (Figure 7F). Our results collectively point that in the presence of Wnt ligand signaling, Xarhgef3.2 physically interacts with Dsh2 via Daam1 by means of its $\mathrm{N}$ terminal region and activates downstream RhoA which is necessary for CE cell movement in Xenopus development.

\section{Discussion}

In the present study, we hypothesized that cell fate determination of germ layers and subsequent gastrulation movement are linked. In this perspective, we aimed to uncover the pathway links between these two events. We focused on the possible interaction of the Wnt-PCP component with the established Bmp gradient early gastrula of Xenopus embryos. In the current study, we reasoned that Bmp gradient inversely regulates gastrulation cell movement and found that transcription of Xarhgef3.2 was regulated by the Bmp gradient. Altogether, the present study may add clues to embryonic morphogenesis in which cell fate determination of germ layers and subsequent gastrulation movement may be linked via transcriptional modulation of small GTPase regulators which play roles in the regulation of all the morphogenetic movements of developing gastrula embryos.

\subsection{BMP Gradient Inversely Correlates with CE Movement}

In this study, we first inquired about the involvement of the Bmp gradient as linking germ layer determination and gastrulation. The reasoning was based on the following: first, the spatial expression and activity pattern of Bmp are known, and Bmp signal gradient is high in the ventral side and low in the dorsal side of an embryo [48]. In contrast, in early gastrulation, CE cell movement is almost absent in the ventral side and highly present in the dorsal lip region where the Bmp gradient is at a minimum [58]. The spatial patterns of Bmp activity and CE activity are inversely correlated. Second, the temporal involvement of Bmp is compelling in that Bmp is a morphogen which actively participates in germ layer determination before gastrulation $[47,48]$ as well as dorsoventral patterning of the mesoderm and the ectoderm (neuroectoderm vs. ectoderm) before and during gastrulation [59]. Bmp gradient has a role in the timely onset of gastrulation. Therefore, it is possible that Bmp gradient before gastrulation may prepare for subsequent $\mathrm{CE}$ movement of gastrulation. Third, according to the loss- and gain-of-function studies of Bmp, depletion of $\mathrm{Bmp}$ in the ventral side leads to formation of a secondary axis, whereas ectopic expression of Bmp in the dorsal region results in a ventralized embryo being headless with axis shortening [34]. Although whether secondary axis formation caused by depletion of Bmp requires active $C E$ movement needs to be examined, the results indicate that the establishment of CE cell movement is dependent on Bmp gradient. Details of how Bmp gradient affects cell movement without affecting fate determination need to be understood. Fourth, there was an elongation study of ACs performed by Suzuki et al. [44] where coinjection of $d n b r$ dramatically increased the elongation caused by the injection of activin and fgf in ACs. Since elongation is followed by the morphogenetic movement of involuting cells of the dorsal marginal zone during gastrulation [60], this elongation via Bmp inhibition strongly advocates for its correlation with gastrulation movement. In addition, it has been reported that Bmp gradient has an instructive role in establishing a reverse gradient of cellcell adhesiveness to determine the direction of lateral mesodermal cell migration during 
dorsal convergence in zebrafish gastrula [61]. A repulsive role for Bmp gradient on lateral migrating mesodermal cells via diminishing cell-cell adhesion which is independent of fate specification and noncanonical Wnt signaling has also been reported [61]. Even though an interconnection between the Bmp gradient and gastrulation movement in gastrula embryos seems plausible, the studies of the involvement of the Bmp gradient in CE are limited, and more research is needed to support the conjecture that Bmp gradient regulates cell movement independently from cell fate specification.

We hypothesized Bmp as a key linking molecule between early primordial three germ layers formation and subsequent gastrulation movement, leading to having each germ layer localized to a specific region in a whole embryo. In this respect, we wonder whether the partial secondary axis formed by inhibition of the Bmp signal in the ventral side requires active CE movement. In our experiments, the secondary axis formed by the DNBR injection was abolished by DN-RhoA co-injection (Figure 1B,C), indicating that secondary axis formation also requires activation of small GTPases RhoA, possibly as a component of the Wnt-PCP pathway of CE movement. This Wnt-PCP activation for secondary axis formation in a whole embryo and enhanced elongation in ACs [44] and VMZ explants (Supplementary Figure S1B) could then be modulated in various ways, including signal cross-talks via posttranslational modification, transcriptional regulation of a Wnt-PCP component, or both under the condition of BMP inhibition. Bmp inhibition in the ventral mesoderm converts the ventral mesoderm to the dorsal mesoderm which contains the organizer character [62]. Organizer transplantation to the ventral side of another embryo results in formation of a duplicated complete axis [63]. Secondary axis formation may require the dorsal mesoderm as the leading cells (bottle cells) as well as activation of Wnt-PCP signaling for proper gastrulation movement. From this set of observations, in the current study, we focused on the identification of the responsible regulators of small GTPases possibly involved in the Wnt-PCP pathway, whose expression would be upregulated under a BMP signaling block such as ectopic DNBR expression.

\subsection{Bmp Inhibition Upregulates Expression of a Regulator of Small GTPases, Xarhgef3.2}

Bmp depletion converts the ventral mesoderm to the dorsal mesoderm and leads to elongation of VMZ explants (Supplementary Figure S1B). We next examined the possibility that Bmp inhibition may upregulate expression of the genes related to cell movement of gastrula embryos. Bmp inhibition, activin or Fgf treatment in the ACs resulted in formation of different germ layers, namely neuroectoderm, organizer (dorsal mesoderm), and lateral mesoderm, respectively. Activin has been shown to transform ectodermal explant cells to three different fates of the dorsal mesoderm, endoderm and neuroectoderm along with elongation in ACs. Fgf also leads to mesoderm formation of ACs with elongation being a little less than that of activin. Meantime, DNBR induces neuroectoderm formation in ACs but DNBR alone results in minor elongation of ACs compared to that of activin and Fgf. Interestingly, combined treatment of DNBR with activin or Fgf results in much enhanced elongation [44], which shows that Bmp signaling in combination with activin or Fgf has an additional role in elongation. The elongation of ACs could possibly be affected by CE movement and Wnt-PCP activation by modulating the activity or the expression of Wnt-PCP component molecules. Since all the three conditions of activin, Fgf, and Bmp inhibition commonly lead to elongation accompanying fate change in ACs, this elongation induction character was used to identify any modulators involved in cell movement of gastrula embryos, including modulators of the Wnt-PCP component gene whose expression would be increased in all the three conditions. We performed a microarray analysis using RNA from DNBR-injected, activin- or Fgf-treated ACs. Xarhgef3.2.L was found to become commonly upregulated in all the three instances (Figure 1D).

In the current study, we mainly focused on characterization of Xarhgef3.2 whose transcription was upregulated when Bmp signaling was inhibited. Besides Xarhgef3.2, it would be interesting, regulated under BMP inhibition/stimulation conditions, to screen for additional components of the stimulatory/inhibitory Wnt-PCP pathway, respectively. 
In zebrafish, it has been observed that a single gradient of Bmp activity specifies the cell fate as well as regulates the process of CE by negatively modulating expression of the noncanonical Wnt ligands, wnt11 and wnt5a [10]. In addition, a dorsoventral gradient of wnt11b was detected at stage 11 by Tada and Smith, 2000 [13], and also in the more recent transcriptome analysis of dorsal and ventral halves at stage 10.5 in Xenopus by Ding et al., 2017 [64]. In the present study, however, wnt11b expressions were not very different in the DMZ and VMZ explants at stage 12 (Figure 2C), and wnt11b expression was not significantly modulated by Bmp overexpression in the DMZ or BMP inhibition in the VMZ according to the RT-PCR analysis (Figure 2E). This suggested that wnt11b expression needs to be confirmed in more stages and with better quantification in early Xenopus gastrula.

The increased expression of Xarhgef3.2 was reported by Hufton et al. (2005) [49] and Popov et al. (2017) [65]. Hufton et al. screened for Xarhgef3.2 using the same Affimatrix oligonucleotide microarray as in our study. Xarhgef3.2 was upregulated at stage 10.5 by joint ectopic overexpression of $n \circ g$ and $d k k-1$ cDNA, respective inhibitors of the BMP and Wnt pathways in the VMZ. Xarhgef3.2 was not expressed with ectopic overexpression nog or $d k k-1$ alone. In the present study, Xarhgef3.2 levels were detected under the BMP inhibition condition and without the Wnt inhibition in both the VMZ and AC explants. In comparison, we used the VMZ explants injected with DNBR mRNA and Hufton et al. used cDNA to ensure that the molecules were only expressed after the start of zygotic transcription (mid-blastula transition), thereby mimicking the endogenous regulation of these genes. In addition, they observed arhgef3.2 expressions via in situ analysis using whole embryos, and we used the VMZ explants. At the present time, we do not know the exact reason how the two experiments lead to the Xarhgef3.2 expression differences observed. More recently, Popov et al. also reported arhgef3 as one of the regulators which are differentially enriched in the DMZ of Xenopus at stage 11 [65]. Any roles for activin, Fgf, and Bmp gradient changes in modulation of the target molecule such as its post-translational modification for its activation and deactivation in the Wnt-PCP component pathway do merit a closer look. Regarding Xarhgef3.2, it also remains unclear whether its transcriptional upregulation was mainly due to Bmp signal inhibition or it was also independently mediated by Fgf and activin signaling. We need to remember that there is an inhibitory property of Fgf signaling on the Bmp pathway through Bmp intracellular signal mediator Smad1 link region phosphorylation [66]. Similarly, there is also the antagonistic behavior of activin signaling on Bmp signaling through induction of BMP antagonists such as chrd, nog, and cerberus [67]. We may assume that upregulation of Wnt-PCP component Xarhgef3.2 via Bmp inhibition is at least partially common. In addition, the fact that combination treatment with $\mathrm{DNBR} /$ activin or DNBR/Fgf results in a significantly more enhanced elongation [44] (our unpublished data) provides for the possibility of additional modes of Wnt-PCP component Xarhgef3.2 being regulated, such as its post-translational modification or regulation of its intracellular localization.

\subsection{Xarhgef3.2 Is a Component of Wnt-PCP Signaling without Affecting Fate Determination}

We found that Xarhgef3.2 is highly expressed in the DMZ and less so in the VMZ (Figure 2C). In the present study, we tried to provide evidence on Xarhgef3.2 as a candidate component of Wnt-PCP signaling involved in CE movement. Our claim of CE and Wnt-PCP being linked with Arhgef3.2 functioning are supported by the following: first, the function of another tissue-specific RhoGEF protein, plekhg5, has been reported in apical constriction of bottle cells of gastrulation in Xenopus embryos. However, apical constriction activity of bottle cells is not shared by arhgef3 [68]. Second, Xarhgef3.2 binds to a noncanonical Wnt-PCP component, Daam1 (Figure 7D). Third, Arhgef3.2 binding with Dsh2 is enhanced by noncanonical Wnt11 but not by canonical Wnt8 (Figure 7A). Fourth, both AC elongation from activin treatment and DMZ explant elongation are abolished by the Xarhgef3.2 MO without obviously affecting gene expression patterns (Figure 4D-F and Figure 5F). Fifth, the reduced elongation of DMZ explants via activation or deactivation of each Wnt-PCP component alone is rescued by co-injection with the Xarhgef3.2 partner with an opposite 
activity (WT-Xarhgef3.2 MO vs. Xarhgef3.2), respectively (Figure 5F). The expression pattern of Xarhgef3.2 is distinct from those of other well-characterized RhoGEFs (Net and Wgef) in Xenopus. The expression levels of the known RhoGEFs, Xnet and Xwgef, are similar in the DMZ and the VMZ (Figure 2C). This suggests that Xarhgef3.2 is a crucial component of Wnt-PCP that is functionally involved in CE movements and might be linked to BMP signal gradient. As summarized above, we provide multiple pieces of evidence to decipher the role of Xarhgef3.2 in noncanonical Wnt-PCP signaling and how it efficiently regulates CE. First, Xarhgef3.2 is mainly expressed in the DMZ where CE is highly active and colocalizes in the membrane with RhoA (Figure 2). Xarhgef3.2 also modulates gastrulation without affecting the cell fate (Figure 3A,D and 4B,D,E), and it specifically activates RhoA (Figure 5). N-terminal region of Xarhgef3.2 interacts with downstream Wnt signal mediators, Dsh2 and Daam1 (Figures 6 and 7). The results of RhoA-specific activation by Xarhgef3.2 are reproducible, also seen in a previous report of human Arhgef3 [31]. A previous observation of Xenopus Wgef binding to Daam1 through its N-terminal domain [30] is also similar to our results with respect to Xarhgef3.2 interacting with Daam1 (Figure 7C,D). In the present study, we emphasized that Xarhgef3.2 is a component of Wnt-PCP signaling and its expression is modulated by the Bmp gradient. Although we tried to provide some evidence that Xarhgef3.2 is a functional component of noncanonical Wnt-PCP signaling involved in CE movement of gastrula embryos, the limitation of the present work remained to clarify whether other movements are also affected by Xarhgef3.2 during the gastrulation movement. In summary, we propose a model for Bmp gradient modulation of Xarhgef3.2 gradient via modulation of its expression, which in turn regulates cell movement in gastrula embryos (Figure 8). Human Arhgef3 has been linked with osteoporosis [69] and has oncogenic correlation with nasopharyngeal carcinoma (NPC), where a gain of function results in NPC tumorigenesis and metastasis and loss of function dramatically induces apoptosis in cancer cells [70]. As human and Xenopus Arhgef3.2 display high sequence homology, it will be interesting to see whether Bmp has a transcriptional regulatory role for human Arhgef3 as well and whether in human cells activin/TGF-beta/Fgf signaling modifies its physiological functions, leading us to define a common mechanism in understanding its role in cancer cells as well. Altogether, our study may provide an additional insight on the role of Bmp gradient on gastrula cell movement in addition to its known function in germ layer specification of vertebrate embryogenesis.
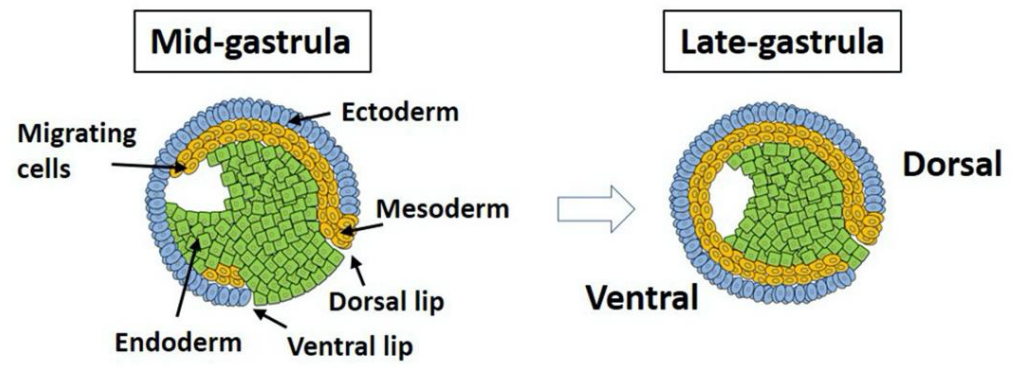

Ventral

BMP gradient in the mesoderm

Dorsal

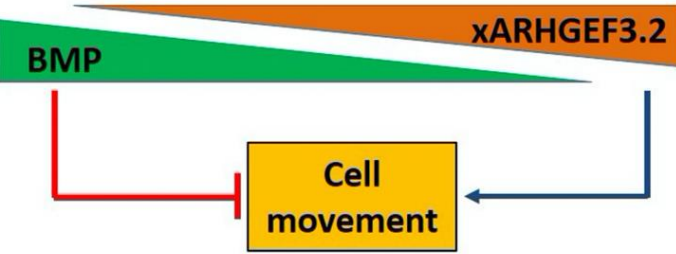

Figure 8. Proposed model of the Bmp-Arhgef3.2 gradient in the modulation of cell movement in the gastrula Xenopus embryos. In the proposed model, Bmp gradient inversely modulates expression of Xarhgef3.2, which in turn regulates cell movement in gastrula embryos, leading to active gastrulation movement in the dorsal region and a weak gastrulation movement in the ventral region of the embryos. 
Supplementary Materials: The following supporting information can be downloaded at https: / / www.mdpi.com/article/10.3390/cells11010044/s1. Figure S1: Dominant negative form of RhoA (DN-RhoA) suppressed the secondary axis formation induced by DNBR. Figure S2: Alignment of Xenopus arhgef3.2 sequences with human, chick, lizard, zebrafish and mouse ARHGEF3 sequences. Figure S3: Truncated nuclear localization signal (NLS) block Arhgef3.2 nuclear localization. Figure S4: Arhgef3 is co-localized with Dsh and Daam-1. Table S1: Normalized and analyzed microarray data of upregulated genes from activin treatment. Table S2: Normalized and analyzed microarray data of upregulated genes from Dnbr treatment. Table S3: Normalized and analyzed microarray data of upregulated genes from Fgf treatment.

Author Contributions: Conceptualization, J.Y. and J.K.; methodology, formal analysis, V.K., R.S.G. and J.K.; investigation, J.Y. and J.K.; writing—original draft preparation, J.K., J.Y. and R.S.G.; writingreview and editing, J.Y. and J.K.; supervision, J.K., S.-C.K. and U.L.; project administration, J.K., U.L. and S.P.; funding acquisition, J.K., U.L. and S.P. All authors have read and agreed to the published version of the manuscript.

Funding: This article was supported by the Basic Science Research Program through the National Research Foundation of Korea (NRF), which is funded by the Ministry of Education, Science, and Technology of Korea (2016R1D1A1B02008770, 2018M3C7A1056285, 2021R1A4A1027355, and 2021M3H9A1097557).

Institutional Review Board Statement: This study was conducted in accordance with the Institutional Animal Care and Use Committee (IACUC) regulations of Hallym University (Hallym 2019-79, 2019-80). All our research team members attended educational and training courses for the appropriate care and use of the experimental animals. Adult X. laevis were maintained in suitable containers under a $12 \mathrm{~h}$ light/dark (LD 12:12 h) cycle at $18^{\circ} \mathrm{C}$, tended by authorized personnel and according to the Institute of Laboratory Animal Guidelines Resources of Hallym University.

Informed Consent Statement: Not applicable.

Data Availability Statement: Original data are available on reasonable request from the corresponding authors.

Conflicts of Interest: The authors have no potential conflicts of interest to disclose.

\section{References}

1. Piccolo, S.; Sasai, Y.; Lu, B.; De Robertis, E.M. Dorsoventral patterning in Xenopus: Inhibition of ventral signals by direct binding of chordin to BMP-4. Cell 1996, 86, 589-598. [CrossRef]

2. Roszko, I.; Sawada, A.; Solnica-Krezel, L. Regulation of convergence and extension movements during vertebrate gastrulation by the Wnt/PCP pathway. Semin. Cell Dev. Biol. 2009, 20, 986-997. [CrossRef]

3. Keller, R.; Davidson, L.; Edlund, A.; Elul, T.; Ezin, M.; Shook, D.; Skoglund, P. Mechanisms of convergence and extension by cell intercalation. Philos. Trans. R. Soc. Lond. B Biol. Sci. 2000, 355, 897-922. [CrossRef]

4. Piccolo, S.; Agius, E.; Leyns, L.; Bhattacharyya, S.; Grunz, H.; Bouwmeester, T.; De Robertis, E.M. The head inducer Cerberus is a multifunctional antagonist of Nodal, BMP and Wnt signals. Nature 1999, 397, 707-710. [CrossRef] [PubMed]

5. Jones, C.M.; Smith, J.C. Establishment of a BMP-4 morphogen gradient by long-range inhibition. Dev. Biol. 1998, 194, 12-17. [CrossRef] [PubMed]

6. Kumar, V.; Umair, Z.; Kumar, S.; Lee, U.; Kim, J. Smad2 and Smad3 differentially modulate chordin transcription via direct binding on the distal elements in gastrula Xenopus embryos. Biochem. Biophys. Res. Commun. 2021, 559, 168-175. [CrossRef]

7. Zoltewicz, J.S.; Gerhart, J.C. The Spemann organizer of Xenopus is patterned along its anteroposterior axis at the earliest gastrula stage. Dev. Biol. 1997, 192, 482-491. [CrossRef]

8. Sasai, Y.; Lu, B.; Steinbeisser, H.; De Robertis, E.M. Regulation of neural induction by the Chd and Bmp-4 antagonistic patterning signals in Xenopus. Nature 1995, 376, 333-336. [CrossRef]

9. Wang, R.N.; Green, J.; Wang, Z.; Deng, Y.; Qiao, M.; Peabody, M.; Zhang, Q.; Ye, J.; Yan, Z.; Denduluri, S.; et al. Bone Morphogenetic Protein (BMP) signaling in development and human diseases. Genes Dis. 2014, 1, 87-105. [CrossRef] [PubMed]

10. Myers, D.C.; Sepich, D.S.; Solnica-Krezel, L. Bmp activity gradient regulates convergent extension during zebrafish gastrulation. Dev. Biol. 2002, 243, 81-98. [CrossRef]

11. Jones, C.M.; Lyons, K.M.; Lapan, P.M.; Wright, C.V.; Hogan, B.L. DVR-4 (bone morphogenetic protein-4) as a posterior-ventralizing factor in Xenopus mesoderm induction. Development 1992, 115, 639-647. [CrossRef] [PubMed]

12. Graff, J.M.; Thies, R.S.; Song, J.J.; Celeste, A.J.; Melton, D.A. Studies with a Xenopus BMP receptor suggest that ventral mesoderminducing signals override dorsal signals in vivo. Cell 1994, 79, 169-179. [CrossRef] 
13. Tada, M.; Concha, M.L.; Heisenberg, C.P. Non-canonical Wnt signalling and regulation of gastrulation movements. Semin. Cell Dev. Biol. 2002, 13, 251-260. [CrossRef]

14. Kuhl, M. Non-canonical Wnt signaling in Xenopus: Regulation of axis formation and gastrulation. Semin. Cell Dev. Biol. 2002, 13, 243-249. [CrossRef]

15. Wallingford, J.B.; Harland, R.M. Xenopus Dishevelled signaling regulates both neural and mesodermal convergent extension: Parallel forces elongating the body axis. Development 2001, 128, 2581-2592. [CrossRef]

16. Wallingford, J.B.; Rowning, B.A.; Vogeli, K.M.; Rothbacher, U.; Fraser, S.E.; Harland, R.M. Dishevelled controls cell polarity during Xenopus gastrulation. Nature 2000, 405, 81-85. [CrossRef]

17. Hens, M.D.; Nikolic, I.; Woolcock, C.M. Regulation of Xenopus embryonic cell adhesion by the small GTPase, rac. Biochem. Biophys. Res. Commun. 2002, 298, 364-370. [CrossRef]

18. Wunnenberg-Stapleton, K.; Blitz, I.L.; Hashimoto, C.; Cho, K.W. Involvement of the small GTPases XRhoA and XRnd1 in cell adhesion and head formation in early Xenopus development. Development 1999, 126, 5339-5351. [CrossRef] [PubMed]

19. Drechsel, D.N.; Hyman, A.A.; Hall, A.; Glotzer, M. A requirement for Rho and Cdc42 during cytokinesis in Xenopus embryos. Curr. Biol. 1997, 7, 12-23. [CrossRef]

20. Kishi, K.; Sasaki, T.; Kuroda, S.; Itoh, T.; Takai, Y. Regulation of cytoplasmic division of Xenopus embryo by rho p21 and its inhibitory GDP/GTP exchange protein (rho GDI). J. Cell Biol. 1993, 120, 1187-1195. [CrossRef]

21. Penzo-Mendez, A.; Umbhauer, M.; Djiane, A.; Boucaut, J.C.; Riou, J.F. Activation of Gbetagamma signaling downstream of Wnt-11/Xfz7 regulates Cdc42 activity during Xenopus gastrulation. Dev. Biol. 2003, 257, 302-314. [CrossRef]

22. Habas, R.; Dawid, I.B.; He, X. Coactivation of Rac and Rho by Wnt/Frizzled signaling is required for vertebrate gastrulation Genes Dev. 2003, 17, 295-309. [CrossRef] [PubMed]

23. Choi, S.C.; Han, J.K. Xenopus Cdc42 regulates convergent extension movements during gastrulation through Wnt/Ca2+ signaling pathway. Dev. Biol. 2002, 244, 342-357. [CrossRef]

24. Habas, R.; Kato, Y.; He, X. Wnt/Frizzled activation of Rho regulates vertebrate gastrulation and requires a novel Formin homology protein Daam1. Cell 2001, 107, 843-854. [CrossRef]

25. Cherfils, J.; Zeghouf, M. Regulation of small GTPases by GEFs, GAPs, and GDIs. Physiol. Rev. 2013, 93, 269-309. [CrossRef]

26. Zheng, Y. Dbl family guanine nucleotide exchange factors. Trends Biochem. Sci. 2001, 26, 724-732. [CrossRef]

27. Tanegashima, K.; Zhao, H.; Dawid, I.B. WGEF activates Rho in the Wnt-PCP pathway and controls convergent extension in Xenopus gastrulation. EMBO J. 2008, 27, 606-617. [CrossRef] [PubMed]

28. Miyakoshi, A.; Ueno, N.; Kinoshita, N. Rho guanine nucleotide exchange factor xNET1 implicated in gastrulation movements during Xenopus development. Differentiation 2004, 72, 48-55. [CrossRef]

29. Kristelly, R.; Gao, G.; Tesmer, J.J. Structural determinants of RhoA binding and nucleotide exchange in leukemia-associated Rho guanine-nucleotide exchange factor. J. Biol. Chem. 2004, 279, 47352-47362. [CrossRef]

30. Arthur, W.T.; Ellerbroek, S.M.; Der, C.J.; Burridge, K.; Wennerberg, K. XPLN, a guanine nucleotide exchange factor for RhoA and RhoB, but not RhoC. J. Biol. Chem. 2002, 277, 42964-42972. [CrossRef]

31. Smith, J.C.; Slack, J.M. Dorsalization and neural induction: Properties of the organizer in Xenopus laevis. J. Embryol. Exp. Morphol. 1983, 78, 299-317. [CrossRef] [PubMed]

32. Kumar, S.; Umair, Z.; Kumar, V.; Kumar, S.; Lee, U.; Kim, J. Foxd411.1 negatively regulates transcription of neural repressor ventx1.1 during neuroectoderm formation in Xenopus embryos. Sci. Rep. 2020, 10, 16780. [CrossRef] [PubMed]

33. Nieuwkoop, P.D.; Faber, J.; Gerhart, J.; Kirschner, M. Normal Table of Xenopus Laevis (Daudin): A Systematical and Chronological Survey of the Development from the Fertilized Egg till the End of Metamorphosis; Garland Science: New York, NY, USA, 1994.

34. Suzuki, A.; Thies, R.S.; Yamaji, N.; Song, J.J.; Wozney, J.M.; Murakami, K.; Ueno, N. A truncated bone morphogenetic protein receptor affects dorsal-ventral patterning in the early Xenopus embryo. Proc. Natl. Acad. Sci. USA 1994, 91, 10255-10259. [CrossRef] [PubMed]

35. Xu, R.-H.; Kim, J.; Taira, M.; Zhan, S.; Sredni, D.; Kung, H. A dominant negative bone morphogenetic protein 4 receptor causes neuralization in Xenopus ectoderm. Biochem. Biophys. Res. Commun. 1995, 212, 212-219. [CrossRef]

36. Umair, Z.; Kumar, S.; Rafiq, K.; Kumar, V.; Reman, Z.U.; Lee, S.H.; Kim, S.; Lee, J.Y.; Lee, U.; Kim, J. Dusp1 modulates activin/smad2 mediated germ layer specification via FGF signal inhibition in Xenopus embryos. Anim. Cells Syst. 2020, 24, 359-370. [CrossRef]

37. Grow, M.; Neff, A.W.; Mescher, A.L.; King, M.W. Global analysis of gene expression in Xenopus hindlimbs during stage-dependent complete and incomplete regeneration. Dev. Dyn. 2006, 235, 2667-2685. [CrossRef]

38. Dereeper, A.; Audic, S.; Claverie, J.M.; Blanc, G. BLAST-EXPLORER helps you building datasets for phylogenetic analysis. BMC Evol. Biol. 2010, 10, 8. [CrossRef]

39. Kumar, V.; Goutam, R.S.; Umair, Z.; Park, S.; Lee, U.; Kim, J. Foxd411.1 Negatively Regulates Chordin Transcription in Neuroectoderm of Xenopus Gastrula. Cells 2021, 10, 2779. [CrossRef]

40. Kumar, S.; Umair, Z.; Kumar, V.; Lee, U.; Choi, S.C.; Kim, J. Ventx1.1 competes with a transcriptional activator Xcad2 to regulate negatively its own expression. BMB Rep. 2019, 52, 403-408. [CrossRef]

41. Umair, Z.; Kumar, S.; Kim, D.H.; Rafiq, K.; Kumar, V.; Kim, S.; Park, J.B.; Lee, J.Y.; Lee, U.; Kim, J. Ventx1.1 as a Direct Repressor of Early Neural Gene zic3 in Xenopus laevis. Mol. Cells 2018, 41, 1061-1071. [CrossRef] 
42. Harland, R.M. In situ hybridization: An improved whole-mount method for Xenopus embryos. Methods Cell Biol. 1991, 36, 685-695. [PubMed]

43. Hallonet, M.; Hollemann, T.; Wehr, R.; Jenkins, N.A.; Copeland, N.G.; Pieler, T.; Gruss, P. Vax1 is a novel homeobox-containing gene expressed in the developing anterior ventral forebrain. Development 1998, 125, 2599-2610. [CrossRef] [PubMed]

44. Suzuki, A.; Shioda, N.; Ueno, N. Bone morphogenetic protein acts as a ventral mesoderm modifier in early Xenopus embryos. Dev. Growth Differ. 1995, 37, 581-588. [CrossRef]

45. Tahinci, E.; Symes, K. Distinct functions of Rho and Rac are required for convergent extension during Xenopus gastrulation. Dev. Biol. 2003, 259, 318-335. [CrossRef]

46. Kumar, V.; Goutam, R.S.; Park, S.; Lee, U.; Kim, J. Functional Roles of FGF Signaling in Early Development of Vertebrate Embryos. Cells 2021, 10, 2148. [CrossRef] [PubMed]

47. Hemmati-Brivanlou, A.; Thomsen, G.H. Ventral mesodermal patterning in Xenopus embryos: Expression patterns and activities of BMP-2 and BMP-4. Dev. Genet. 1995, 17, 78-89. [CrossRef] [PubMed]

48. Fainsod, A.; Steinbeisser, H.; De Robertis, E.M. On the function of BMP-4 in patterning the marginal zone of the Xenopus embryo. EMBO J. 1994, 13, 5015-5025. [CrossRef] [PubMed]

49. Hufton, A.L.; Vinayagam, A.; Suhai, S.; Baker, J.C. Genomic analysis of Xenopus organizer function. BMC Dev. Biol. 2006, 6, 27. [CrossRef]

50. Lee, S.Y.; Yoon, J.; Lee, H.S.; Hwang, Y.S.; Cha, S.W.; Jeong, C.H.; Kim, J.I.; Park, J.B.; Lee, J.Y.; Kim, S.; et al. The function of heterodimeric AP-1 comprised of c-Jun and c-Fos in activin mediated Spemann organizer gene expression. PLoS ONE 2011, 6, e21796. [CrossRef]

51. Yoon, J.; Kim, J.H.; Lee, S.Y.; Kim, S.; Park, J.B.; Lee, J.Y.; Kim, J. PV.1 induced by FGF-Xbra functions as a repressor of neurogenesis in Xenopus embryos. BMB Rep. 2014, 47, 673-678. [CrossRef]

52. Lee, S.Y.; Lim, S.K.; Cha, S.W.; Yoon, J.; Lee, S.H.; Lee, H.S.; Park, J.B.; Lee, J.Y.; Kim, S.C.; Kim, J. Inhibition of FGF signaling converts dorsal mesoderm to ventral mesoderm in early Xenopus embryos. Differentiation 2011, 82, 99-107. [CrossRef] [PubMed]

53. You, J.S.; Singh, N.; Reyes-Ordonez, A.; Khanna, N.; Bao, Z.; Zhao, H.; Chen, J. ARHGEF3 Regulates Skeletal Muscle Regeneration and Strength through Autophagy. Cell Rep. 2021, 34, 108594. [CrossRef] [PubMed]

54. Khanna, N.; Fang, Y.; Yoon, M.S.; Chen, J. XPLN is an endogenous inhibitor of mTORC2. Proc. Natl. Acad. Sci. USA 2013, 110, 15979-15984. [CrossRef]

55. Kwan, K.M.; Kirschner, M.W. Xbra functions as a switch between cell migration and convergent extension in the Xenopus gastrula. Development 2003, 130, 1961-1972. [CrossRef]

56. Wallingford, J.B.; Fraser, S.E.; Harland, R.M. Convergent extension: The molecular control of polarized cell movement during embryonic development. Dev. Cell 2002, 2, 695-706. [CrossRef]

57. Sokol, S.Y. Analysis of Dishevelled signalling pathways during Xenopus development. Curr. Biol. 1996, 6, 1456-1467. [CrossRef]

58. Clement, J.H.; Fettes, P.; Knochel, S.; Lef, J.; Knochel, W. Bone morphogenetic protein 2 in the early development of Xenopus laevis. Mech. Dev. 1995, 52, 357-370. [CrossRef]

59. Dale, L.; Howes, G.; Price, B.M.; Smith, J.C. Bone morphogenetic protein 4: A ventralizing factor in early Xenopus development Development 1992, 115, 573-585. [CrossRef] [PubMed]

60. Keller, R.; Danilchik, M. Regional expression, pattern and timing of convergence and extension during gastrulation of Xenopus laevis. Development 1988, 103, 193-209. [CrossRef] [PubMed]

61. von der Hardt, S.; Bakkers, J.; Inbal, A.; Carvalho, L.; Solnica-Krezel, L.; Heisenberg, C.P.; Hammerschmidt, M. The Bmp gradient of the zebrafish gastrula guides migrating lateral cells by regulating cell-cell adhesion. Curr. Biol. 2007, 17, 475-487. [CrossRef]

62. Nishimatsu, S.; Thomsen, G.H. Ventral mesoderm induction and patterning by bone morphogenetic protein heterodimers in Xenopus embryos. Mech. Dev. 1998, 74, 75-88. [CrossRef]

63. Cho, K.W.; Blumberg, B.; Steinbeisser, H.; De Robertis, E.M. Molecular nature of Spemann's organizer: The role of the Xenopus homeobox gene goosecoid. Cell 1991, 67, 1111-1120. [CrossRef]

64. Ding, Y.; Colozza, G.; Zhang, K.; Moriyama, Y.; Ploper, D.; Sosa, E.A.; Benitez, M.D.J.; De Robertis, E.M. Genome-wide analysis of dorsal and ventral transcriptomes of the Xenopus laevis gastrula. Dev. Biol. 2017, 426, 176-187. [CrossRef] [PubMed]

65. Popov, I.K.; Kwon, T.; Crossman, D.K.; Crowley, M.R.; Wallingford, J.B.; Chang, C. Identification of new regulators of embryonic patterning and morphogenesis in Xenopus gastrulae by RNA sequencing. Dev. Biol. 2017, 426, 429-441. [CrossRef] [PubMed]

66. Pera, E.M.; Ikeda, A.; Eivers, E.; De Robertis, E.M. Integration of IGF, FGF, and anti-BMP signals via Smad1 phosphorylation in neural induction. Genes Dev. 2003, 17, 3023-3028. [CrossRef] [PubMed]

67. Canalis, E.; Economides, A.N.; Gazzerro, E. Bone morphogenetic proteins, their antagonists, and the skeleton. Endocr. Rev. 2003, 24, 218-235. [CrossRef]

68. Popov, I.K.; Ray, H.J.; Skoglund, P.; Keller, R.; Chang, C. The RhoGEF protein Plekhg5 regulates apical constriction of bottle cells during gastrulation. Development 2018, 145, dev168922. [CrossRef]

69. Mullin, B.H.; Prince, R.L.; Mamotte, C.; Spector, T.D.; Hart, D.J.; Dudbridge, F.; Wilson, S.G. Further genetic evidence suggesting a role for the RhoGTPase-RhoGEF pathway in osteoporosis. Bone 2009, 45, 387-391. [CrossRef]

70. Liu, T.H.; Zheng, F.; Cai, M.Y.; Guo, L.; Lin, H.X.; Chen, J.W.; Liao, Y.J.; Kung, H.F.; Zeng, Y.X.; Xie, D. The putative tumor activator ARHGEF3 promotes nasopharyngeal carcinoma cell pathogenesis by inhibiting cellular apoptosis. Oncotarget 2016, 7, 25836-25848. [CrossRef] 